\title{
Benefits of mindfulness at work : the role of mindfulness in emotion regulation, emotional exhaustion, and job satisfaction
}

Citation for published version (APA):

Hülsheger, U. R., Alberts, H. J. E. M., Feinholdt, A., \& Lang, J. W. B. (2013). Benefits of mindfulness at work : the role of mindfulness in emotion regulation, emotional exhaustion, and job satisfaction. Journal of Applied Psychology, 98(2), 310-325. https://doi.org/10.1037/a0031313

Document status and date:

Published: 01/03/2013

DOI:

10.1037/a0031313

Document Version:

Publisher's PDF, also known as Version of record

Document license:

Taverne

Please check the document version of this publication:

- A submitted manuscript is the version of the article upon submission and before peer-review. There can be important differences between the submitted version and the official published version of record.

People interested in the research are advised to contact the author for the final version of the publication, or visit the DOI to the publisher's website.

- The final author version and the galley proof are versions of the publication after peer review.

- The final published version features the final layout of the paper including the volume, issue and page numbers.

Link to publication

\footnotetext{
General rights rights.

- You may freely distribute the URL identifying the publication in the public portal. please follow below link for the End User Agreement:

www.umlib.nl/taverne-license

Take down policy

If you believe that this document breaches copyright please contact us at:

repository@maastrichtuniversity.nl

providing details and we will investigate your claim.
}

Copyright and moral rights for the publications made accessible in the public portal are retained by the authors and/or other copyright owners and it is a condition of accessing publications that users recognise and abide by the legal requirements associated with these

- Users may download and print one copy of any publication from the public portal for the purpose of private study or research.

- You may not further distribute the material or use it for any profit-making activity or commercial gain

If the publication is distributed under the terms of Article $25 \mathrm{fa}$ of the Dutch Copyright Act, indicated by the "Taverne" license above, 


\title{
Benefits of Mindfulness at Work: The Role of Mindfulness in Emotion Regulation, Emotional Exhaustion, and Job Satisfaction
}

\author{
Ute R. Hülsheger, Hugo J. E. M. Alberts, Alina Feinholdt, and Jonas W. B. Lang \\ Maastricht University
}

\begin{abstract}
Mindfulness describes a state of consciousness in which individuals attend to ongoing events and experiences in a receptive and non-judgmental way. The present research investigated the idea that mindfulness reduces emotional exhaustion and improves job satisfaction. The authors further suggest that these associations are mediated by the emotion regulation strategy of surface acting. Study 1 was a 5-day diary study with 219 employees and revealed that mindfulness negatively related to emotional exhaustion and positively related to job satisfaction at both the within- and the between-person levels. Both relationships were mediated by surface acting at both levels of analysis. Study 2 was an experimental field study, in which participants $(N=64)$ were randomly assigned to a self-training mindfulness intervention group or a control group. Results revealed that participants in the mindfulness intervention group experienced significantly less emotional exhaustion and more job satisfaction than participants in the control group. The causal effect of mindfulness self-training on emotional exhaustion was mediated by surface acting. Implications for using mindfulness and mindfulness training interventions in organizational research and practice are discussed in conclusion.
\end{abstract}

Keywords: mindfulness, emotional exhaustion, emotional labor, job satisfaction, intervention

In the last three decades, the concept of mindfulness-a state of nonjudgmental attentiveness to and awareness of moment-tomoment experiences (Bishop et al., 2004; Brown \& Ryan, 2003)has received considerable attention in clinical as well as in personality psychology. Sparked by the introduction of mindfulnessbased treatment programs (e.g., mindfulness-based stress reduction [MBSR]: Kabat-Zinn, 1982; mindfulness-based cognitive therapy [MBCT]: Segal, Williams, \& Teasdale, 2002), clinical practitioners have integrated mindfulness in the treatment of a host of emotional and behavioral disorders, such as borderline personality disorder, major depression, chronic pain, or eating disorders (cf. Bishop et al., 2004). This trend has been accompanied by a growing body of empirical evidence for the effectiveness of mindfulness-based interventions (a) to reduce symptoms in clinical samples (for meta-analytic reviews, see Bohlmeijer, Prenger, Taal, \& Cuijpers, 2010; Grossman, Niemann, Schmidt, \& Walach, 2004) and (b) to promote psychological well-being in non-clinical samples (Collard, Avny, \& Boniwell, 2008; Irving, Dobkin, \& Park, 2009). In personality psychology, researchers have focused on

This article was published Online First December 31, 2012.

Ute R. Hülsheger, Alina Feinholdt, and Jonas W. B. Lang, Faculty of Psychology and Neuroscience, Department of Work and Social Psychology, Maastricht University, Maastricht, the Netherlands; Hugo J. E. M. Alberts, Faculty of Psychology and Neuroscience, Clinical Psychological Science, Maastricht University, the Netherlands.

We thank Felix Sion, Evelien Lambrigts, Lies Daenen, Tessa Claes, and Annika Krause for their help in collecting data.

Correspondence concerning this article should be addressed to Ute R. Hülsheger, Faculty of Psychology and Neuroscience, Department of Work and Social Psychology, Maastricht University, P.O. Box 616, 6200 MD Maastricht, the Netherlands. E-mail: ute.hulsheger@maastrichtuniversity.nl naturally occurring variation in mindfulness as a trait, and they have assembled evidence suggesting that mindfulness is distinct from earlier established constructs like openness to experience, neuroticism, emotional intelligence, or absorption (Baer, Smith, Hopkins, Krietemeyer, \& Toney, 2006; Brown \& Ryan, 2003; Brown, Kasser, Ryan, Linley, \& Orzech, 2009; Weinstein, Brown, \& Ryan, 2009). Furthermore, this line of research has also established effects of trait mindfulness on psychological functioning and well-being.

Recently, mindfulness has started to garner attention in the industrial and organizational (IO) psychology literature. Two theoretical articles on the potential role of mindfulness in the workplace have suggested that mindfulness has a relevant role in work-related outcomes such as task performance (Dane, 2011; Glomb, Duffy, Bono, \& Yang, 2011) or physical and psychological health (Glomb et al., 2011). Additionally, two empirical studies appeared: A cross-sectional study investigated direct and indirect relationships between trait mindfulness and work-family balance (Allen \& Kiburz, 2012), and an intervention study compared a mindfulness-based stress reduction program to a yogabased stress reduction program and a no-treatment control group (Wolever et al., 2012). Despite this initial evidence, empirical research on mindfulness in the workplace is still scarce. As Glomb et al. (2011) have noted, the vast majority of studies demonstrating the salutary effects of mindfulness have been conducted outside the work context, using student samples or clinical samples such that empirical findings may not generalize to the work context. Furthermore, Glomb et al. have called for an understanding of "why" and "how" mindfulness relates to employee well-being (p. 116).

In this article, we build upon and extend findings on the role of mindfulness in the workplace and study the impact of mindfulness on emotional exhaustion and job satisfaction in interactive service 
work. A majority of employees are working in the service sector or hold interactive service jobs that require them to interact directly with customers or clients regardless of economic sector (Leidner, 1999). In these jobs, employees are frequently confronted with emotional labor, they face emotionally charged encounters, and they need to manage their emotions as part of their job. Emotional labor makes employees especially prone to emotional exhaustion and reduced job satisfaction (Côté \& Morgan, 2002; Hochschild, 1983; Hülsheger \& Schewe, 2011). Emotional exhaustion is the core burnout dimension (Maslach, Schaufeli, \& Leiter, 2001), whereas job satisfaction is an evaluative judgment of a person's work situation (Weiss, 2002). Both relate to other important organizational outcomes such as task and contextual performance, turnover, and absenteeism (Cropanzano, Rupp, \& Byrne, 2003; Halbesleben \& Bowler, 2007; Harrison, Newman, \& Roth, 2006; Ybema, Smulders, \& Bongers, 2010) making them two key outcomes in the IO and occupational stress literature (Örtqvist \& Wincent, 2010).

Our research seeks to contribute to the emerging literature on mindfulness in the workplace and investigates the role of trait mindfulness, state mindfulness, and a brief mindfulness intervention for these key outcomes. In doing so, we theoretically link previous work on mindfulness with research on emotional labor in organizations and suggest that effects of mindfulness on emotional exhaustion and job satisfaction are mediated by surface acting. We report two studies using various operationalizations of the construct of mindfulness. Study 1 is an observational diary study investigating the link of trait- and state-mindfulness with daily reports of emotional exhaustion and job satisfaction, and the mediating role of surface acting. To our knowledge, this study is the first that simultaneously incorporates trait and state aspects of mindfulness in the context of work. Study 2 complements Study 1 by combining a diary design with a field experiment implementing a brief mindfulness intervention in the experimental group. Study 2 thereby provides insights into the causal nature of relationships between mindfulness, surface acting, emotional exhaustion, and job satisfaction in a field setting.

\section{Mindfulness}

Mindfulness has its roots in Eastern spiritual, especially Buddhist traditions. It has been defined as a state of being in which individuals bring their "attention to the experiences occurring in the present moment, in a nonjudgemental or accepting way" (Baer et al., 2006, p. 27; see also Brown \& Ryan, 2003). Mindfulness has several key characteristics (Brown, Ryan, \& Creswell, 2007): First, mindfulness involves a receptive awareness and registration of inner experiences (emotions, thoughts, behavioral intentions) and external events. Second, mindful information processing is pre-conceptual. In a mindful state, individuals are purely noticing what is happening without evaluating, analyzing, or reflecting upon it. Third, mindfulness is characterized by a present-oriented consciousness in which individuals focus on moment-to-moment experiences rather than thinking about the past or fantasizing about the future. Fourth, mindfulness is an inherent human capacity that varies in strength, both across situations and persons. Research has documented that meditation practice enhances mindfulness and thereby promotes psychological health in clinical and non-clinical samples (for meta-analyses, see Chiesa \& Serretti, 2009; Gross- man et al., 2004). However, mindfulness is not a "rarified state open only to those undergoing ... training" (Brown, Ryan, Loverich, Biegel, \& West, 2011, p. 1042; also see Brown \& Ryan, 2004). Researchers have convincingly argued that mindfulness is a natural human capacity that can be experienced by untrained layperson (Brown \& Ryan, 2003, 2004; Brown, Ryan, et al., 2011; Dane, 2011; Glomb et al., 2011). Natural variations in mindfulness are likely due to variations in genetic predisposition and environmental influences (Davidson, 2010).

\section{Trait and State Mindfulness}

Research investigating mindfulness in the general population involving individuals without any formal meditation experience has shown that mindfulness varies between individuals, that it has trait-like properties and that these can be reliably assessed with a number of self-report measures explicitly designed for untrained respondents (e.g., Brown \& Ryan, 2003; Brown, West, Loverich, \& Biegel, 2011; Feldman, Hayes, Kumar, Greeson, \& Laurenceau, 2007; Walach, Buchheld, Buttenmüller, Kleinknecht, \& Schmidt, 2006). A growing number of studies using these self-report measures have shown that naturally occurring mindfulness is meaningfully related to behavior regulation and psychological health in non-clinical samples without experiences with meditation or mindfulness training (e.g., Allen \& Kiburz, 2012; Bowlin \& Baer, 2012; Brown et al., 2009; Brown \& Ryan, 2003; Kiken \& Shook, 2012; Niemiec et al., 2010; Weinstein et al., 2009).

Most research on natural variations in mindfulness has focused on trait mindfulness (Glomb et al., 2011). However, researchers have repeatedly argued that mindfulness inherently is a psychological state that varies from moment to moment within individuals (Allen \& Kiburz, 2012; Bishop et al., 2004; Brown \& Ryan, 2003; Dane, 2011; Glomb et al., 2011; Heppner et al., 2008; Lau et al., 2006; Robins, Keng, Ekblad, \& Brantley, 2012). This idea stems from the definition of mindfulness as a nonjudgmental experience of the present moment, including inner and outer events, regardless of whether these are positive or negative. Examples of the experience of mindful states stem from a qualitative question we asked participants during the second study reported in this article: A primary school teacher reported that she was fully aware and attentive when a child clung herself to her leg. She reported paying attention to her thoughts and feelings and realized that she was experiencing joy, but also concern, and a bit of anger. A physiotherapist reported that she was fully immersed in the present moment when she was giving a massage and felt every move of her hand and fingers intensely. These examples show that there are countless opportunities to be mindful in our everyday life. The degree to which one is fully immersed in the present moment as well as the duration of such a moment and the frequency with which they occur vary, between and within persons. Individuals with a high natural capacity of being mindful (trait mindfulness) or individuals engaging in regular meditation practice are likely to experience mindfulness more intensely, more often, and over longer periods of time but even these individuals experience days and situations when they are running on autopilot without paying attention to the present moment (see, e.g., Siegel, 2010, p. 28).

Overall, empirical studies on these natural intra-individual variations in mindfulness are still rare and - to our knowledge-even nonexistent in the IO literature. However, a few studies that have 
appeared in the personality literature have shown that state mindfulness can be reliably measured in naturalistic settings with a measure specifically designed for this purpose (Brown \& Ryan, 2003; Weinstein et al., 2009).

In light of the obvious discrepancy between the definition of mindfulness as a state and the current one-sided focus of the literature on trait mindfulness, Study 1 considers mindfulness on both construct levels - at the between-person level (trait) and at the within-person level (state) simultaneously, allowing us to disentangle to what extend the relationships between mindfulness and well-being outcomes are driven by trait- and state-aspects of mindfulness. To shed light on the causal nature of relationships, we complement Study 1 with an experimental field study (Study 2 ), in which the experimental group receives a mindfulness selftraining intervention while the control group does not.

\section{The Role of Mindfulness for Job Satisfaction and Emotional Exhaustion}

Affective events theory (AET; Weiss \& Cropanzano, 1996) suggests that mindfulness may be positively related to job satisfaction. According to AET, work events are proximal causes of employee affective reactions and these reactions, in turn, predict job satisfaction. Previous research has documented that mindfulness facilitates adaptive stress appraisal (Weinstein et al., 2009). The experience of stress emerges not only from an event itself but also from the appraisal of the event as being negative and as exceeding a person's coping capacity (Lazarus \& Follkman, 1984; Weinstein et al., 2009). As the Greek Stoic philosopher Epiktet noted, it is not the things themselves, but our opinions about things that trouble us. When mindful individuals attend to the present moment in a receptive, non-judgmental way, they observe stressful events more objectively and refrain from attaching a meaning or evaluation to it. This helps individuals not to be influenced by biased, negative thought patterns which may lead to an overly dramatic appraisal of the situation. At work, where individuals are confronted with challenging situations every day, mindfulness may thus facilitate adaptive appraisal of stressful events. To the extent that mindfulness affects employees' appraisal of challenging work events as less stressful, these elicit more positive and less negative affective reactions, which, in turn, lead to a more positive evaluative judgment of one's work situation (i.e., job satisfaction).

Furthermore, mindfulness may relate positively to job satisfaction by promoting self-determined behavior (Glomb et al., 2011). By reducing habitual and automatic functioning and drawing attention and awareness to current experiences, mindfulness helps individuals get in contact with their basic values and needs (Shapiro, Carlson, Astin, \& Freedman, 2006). It thereby cultivates self-determined behavior-behavior that is consistent with an individual's needs and values (Brown \& Ryan, 2003; Deci \& Ryan, 1985; Glomb et al., 2011). Given that value attainment and goal self-concordance are closely linked to job satisfaction (Bono \& Judge, 2003; George \& Jones, 1996; Judge, Bono, Erez, \& Locke, 2005), one can expect mindfulness to be positively related to job satisfaction.

Hypothesis 1: (a) Naturally occurring variations in mindfulness at the between-person level (trait), (b) naturally occurring variations in mindfulness at the within-person level (state), and (c) a mindfulness self-training intervention will be positively related to job satisfaction.

We also expect mindfulness to be negatively related to emotional exhaustion. Most work environments confront employees with a variety of demands and challenges. Confronting these demands with self-control and regulatory behavior results in a depletion of cognitive and emotional resources (Baumeister, Bratslavsky, Muraven, \& Tice, 1998), which leads to emotional exhaustion in the long run. In contrast, mindfulness promotes autonomous self-regulation (Brown \& Ryan, 2003), which preserves vitality and energy (Ryan \& Deci, 2008). Accordingly, mindfulness has previously been shown to be associated with vitality in cross-sectional field studies (Allen \& Kiburz, 2012; Brown \& Ryan, 2003). Similarly, a lab study revealed that participants who were instructed to accept and stay in contact with negative emotions (a core component of mindfulness) showed less depletion effects than a control group (Alberts, Schneider, \& Martijn, 2012).

Hypothesis 2: (a) Naturally occurring variations in mindfulness at the between-person level (trait), (b) naturally occurring variations in mindfulness at the within-person level (state), and (c) a mindfulness self-training intervention will be negatively related to emotional exhaustion.

Apart from investigating these main relationships of mindfulness with emotional exhaustion and job satisfaction, the present study aims at shedding further light on a specific process through which mindfulness may facilitate work-related well-being.

\section{The Mediating Role of Emotion Regulation}

The literature has witnessed a number of theoretical advances on (e.g., Bishop et al., 2004; Glomb et al., 2011; Shapiro et al., 2006) and a few empirical tests of (e.g., Allen \& Kiburz, 2012; Coffey \& Hartman, 2008; Weinstein et al., 2009) potential mechanisms underlying the salutary effects of mindfulness. In the present article, we focus on a mechanism that has consistently been described as a central process in the mindfulness literature (emotion/ affect regulation; Bishop et al., 2004; Brown et al., 2007; Glomb et al., 2011; Shapiro et al., 2006) and its manifestation in an applied work-related context. Specifically, we focus on a central element of work-related emotion regulation (i.e., surface acting) as a potential mediator for two main reasons: First, because emotion regulation has repeatedly been proposed as a central mechanism in theoretical work on mindfulness (Bishop et al., 2004; Glomb et al., 2011; Hayes \& Feldman, 2004; Roemer \& Orsillo, 2003; Shapiro et al., 2006). Second, researchers suggested that the effects of mindfulness in the workplace may be particularly strong when emotion regulation is required (Glomb et al., 2011), and we investigate the role of mindfulness in a broad range of service jobs for which emotion regulation is a central demand and a major source of strain (Côté, 2005; Grandey \& Diamond, 2010).

\section{Emotion Regulation at Work}

Employees working in occupations involving interactions with the public are confronted with emotional labor (Hochschild, 1983); they have to comply with emotional display rules that are prescribed by the work role, occupation, or organization and that 
govern the expression of emotions (Rafaeli \& Sutton, 1987). Emotional labor theory suggests that employees make use of two different emotion regulation strategies when they face a discrepancy between actually felt and required emotions-namely, surface acting and deep acting (Grandey, 2000; Holman, MartínezIñigo, \& Totterdell, 2008). A large body of cross-sectional (for a meta-analysis, see Hülsheger \& Schewe, 2011) and longitudinal (Côté \& Morgan, 2002; Hülsheger, Lang, \& Maier, 2010) research documents that surface acting negatively affects employees' job satisfaction and emotional exhaustion, while deep acting has not shown consistent links with these outcomes. Surface acting aims at altering the outward emotional expression without changing the actual feeling, and it involves suppressing negative and faking positive emotional expressions for jobs holding positive emotional display rules (Grandey, 2000). It has been argued that surface acting affects employee well-being in general and emotional exhaustion and job satisfaction in particular, because it is effortful and depletes mental resources, undermines employees' sense of authenticity, and hampers positive social interactions with customers (Brotheridge \& Lee, 2002; Côté, 2005; Grandey, 2003; Holman et al., 2008; Hülsheger \& Schewe, 2011). Research linking emotion regulation strategies to affective events at work has revealed that surface acting is frequently used, especially when employees interact with unpleasant clients and are confronted with stress and anger events (Diefendorff, Richard, \& Yang, 2008; Grandey, Dickter, \& Sin, 2004; Grandey, Tam, \& Brauburger, 2002; Totterdell \& Holman, 2003).

In sum, when it comes to emotion regulation at work, surface acting is the central variable of interest (a) because it is a strategy used frequently to respond to affective events at work among service employees and (b) because it has consistently been shown to be negatively related to job satisfaction and positively to emotional exhaustion.

\section{Surface Acting as a Mediator of the Link of Mindfulness With Emotional Exhaustion and Job Satisfaction}

Referring to Gross's process model of emotion regulation, surface acting can be described as a response-focused form of emotion regulation (Grandey, 2003; Gross, 1998a, 1998b). It targets the modification of the emotional expression after emotional cues have already been evaluated and after experiential, physiological, and behavioral response tendencies have been initiated. The process of surface acting in service jobs holding positive display rules thus involves three sub-processes: (a) a negative evaluation of a work event that (b) triggers response tendencies that (c) need to be overridden by response modulation in terms of faking and/or suppressing emotions.

We expect mindfulness to relate negatively to surface acting because it affects the first two sub-processes. First, through a process called reperceiving (Shapiro et al., 2006), also referred to as decoupling of the self from events (Glomb et al., 2011), mindfulness promotes the experience of internal and external events without evaluation. By deliberately turning attention to the present moment with a non-judgmental attitude, mindful individuals stand back and witness their thoughts and feelings more objectively, without being immersed in them. "We experience what is instead of a commentary or story about what is" (Shapiro et al., 2006, p.
379). Mindfulness creates a separation between the ego and internal/external events (Glomb et al., 2011). Employees may be fully aware that they are being insulted and accused by a customer but by observing the incidence as well as their own thoughts from a meta-perspective they realize that this has nothing to do with their true self. They experience a shift in perspective and realize that what they are experiencing are simply insubstantial thoughts that are no accurate representations of reality and that they eventually pass by (Chambers, Gullone, \& Allen, 2009; Sedlmeier et al., 2012). Support stems from functional magnetic resonance imaging (fMRI) research demonstrating that simply observing and labeling negative emotions reduces the experience and expression of negative emotions by reducing limbic system activation (Glomb et al., 2011; Hariri, Bookheimer, \& Mazziotta, 2000). Work events, such as an interaction with a rude or offensive customer or a complaining patient, will consequently be evaluated in a much less negative and less impactful light.

Second, mindfulness decreases automaticity of mental processes which impedes the second sub-process of surface acting-namely, the automatic triggering of experiential, physiological, and behavioral response tendencies. Various authors have argued that mindfulness promotes self-regulation by interrupting automatic thought and behavior patterns and thereby allowing individuals to react in a self-determined and flexible way (Brown \& Ryan, 2003; Brown et al., 2007; Glomb et al., 2011; Shapiro et al., 2006). Oftentimes, our information processing is heuristic, informed by prior experiences, response patterns, and acquired knowledge. Accordingly, a work event such as a customer who reports difficulties with a product usually triggers a host of response tendencies, for example, anger or fear, physiological arousal, and the impetus to respond harshly. In jobs with positive display rules, these response tendencies in turn need to be suppressed and disguised by surface acting. In contrast, mindfulness involves a nonjudgmental attitude toward thoughts and emotions-positive or negative ones-and promotes the willingness to stay in contact with them without reacting upon them (Bishop et al., 2004). Accordingly, research has shown that mindfulness displays negative links with thought suppression (one element of surface acting; Baer et al., 2006). Similarly, a series of studies by Fetterman, Robinson, Ode, and Gordon (2010) revealed that trait mindfulness was negatively related to impulsivity and positively to self-control, supporting the notion that mindfulness promotes self-regulation by interrupting automatic thought and behavior patterns. Thus, a customer service employee who has been offended may feel sad, ashamed, or angry but instead of reacting upon it, he/she simply notices and observes these negative emotions and accepts them.

Notably, accepting negative emotions does not mean that employees act them out and thereby break display rules by showing them. Quite the contrary, attending to and accepting emotions is more effective in reducing them than trying to change or fight them (Siegel, 2010). Accordingly, mindfulness has been shown to display negative links with verbal aggression, hostility, and anger (Borders, Earleywine, \& Jajodia, 2010). Furthermore, research revealed that mindfulness-based coping with negative thoughts and emotions is more effective in dissolving them and reducing the urge to react upon them than control-based strategies such as suppression (Alberts et al., 2012; Marcks \& Woods, 2005). 
We therefore expect mindfulness to be negatively related to surface acting, which will be negatively related to job satisfaction and positively related to emotional exhaustion.

Hypothesis 3: Surface acting will mediate the relationship of (a) naturally occurring variations in mindfulness at the between-person level (trait), (b) naturally occurring variations in mindfulness at the within-person level (state), and (c) a mindfulness self-training intervention with job satisfaction.

Hypothesis 4: Surface acting will mediate the relationship of (a) naturally occurring variations in mindfulness at the betweenperson level (trait), (b) naturally occurring variations in mindfulness at the within-person level (state), and (c) a mindfulness self-training intervention with emotional exhaustion.

\section{Study 1}

\section{Method}

Sample and procedure. Participants were recruited from various organizations in the Netherlands and the Dutch-speaking part of Belgium. A total of 568 diary booklets were distributed to potentially interested persons holding interactive service jobs. They worked in various organizations, such as hospitals, schools, shops, public offices, nursing homes, or kindergartens. A total of 219 valid questionnaires were returned, resulting in a response rate of $38.6 \%$. The comparably low response rate may be due to the fact that not all questionnaires were distributed individually to participants. Some were handed out by intermediaries (e.g., supervisors, colleagues, team leaders), which might have led to a somewhat lower commitment to complete and return the booklet. Furthermore, participants received no monetary compensation or other kinds of incentives such as gifts which might have increased the response rate (Anseel, Lievens, Scholleart, \& Choragwicka, 2010).

Participants completed a diary twice a day over 5 consecutive work days, providing a total of 1,095 daily records. Each record consisted of two measurement occasions-one report after work, and one in the evening before going to bed. Participants (83\% female, $17 \%$ male) had a mean age of 39.9 years $(S D=12.2)$, and an average tenure of 13 years $(S D=11.6)$. The sample was comprised of nurses $(38.5 \%)$, teachers $(20.4 \%)$, human resources (HR) consultants $(5 \%)$, pedagogues $(5 \%)$, sales clerks $(3.6 \%)$, social workers $(3.2 \%)$, and customer care employees (1.4\%). The remaining participants had other occupations in health care or education or failed to indicate their occupation.

Each day participants were asked to fill in their diary directly after work and in the evening before going to bed. In order to assess employees' daily levels of mindfulness and surface acting during working hours, mindfulness and surface acting were assessed directly after work. To reduce common method bias, outcome variables (job satisfaction and emotional exhaustion) were assessed at a different time point-namely, in the evening.

Measures. Data collection consisted of a general survey and a diary booklet. The general survey was completed once before participants started to fill in the diary booklet. The general survey assessed demographic variables (age, gender, tenure, occupation) and trait mindfulness. All other variables were assessed on a daily basis. Items were answered on 5-point rating scales. Cronbach's alphas are depicted in Table 1.

Mindfulness. Trait mindfulness was assessed with the 15-item Mindful Attention and Awareness Scale (MAAS; Brown \& Ryan, 2003), a measure explicitly designed for and frequently used to measure mindfulness in the general population involving participants who did not undergo any kind of mindfulness training and who have no formal meditation experience. A sample item is "I tend to walk quickly to get where I'm going without paying attention to what I experience along the way" (reverse scored).

Daily levels of mindfulness during work were assessed with the five-item state measure of the MAAS (Brown \& Ryan, 2003). Sample items are "Today I found it difficult to stay focused on what's happening in the present," and "Today I found myself doing things without paying attention." Participants were asked to indicate to what extent these items described their feelings and behavior "during working hours." Answers were scored such that high values indicate high levels of mindfulness.

Surface acting. Surface acting during work was assessed with the respective three-item subscale of Brotheridge and Lee's (2002) Emotional Labor Scale. Since this scale is a global, timeinsensitive measure of emotional labor strategies, the items were adapted to measure daily levels of surface acting. Sample items are "Today I pretended to have emotions that I did not really have," and "Today I resisted expressing my true feelings." Again, participants were instructed to indicate to what extend these items described their behavior "during working hours."

Table 1

Intercorrelations Between Study Variables of Study 1

\begin{tabular}{|c|c|c|c|c|c|c|c|c|}
\hline Variable & Cronbach's $\alpha$ & ICC & $M$ & $S D$ & 2 & 3 & 4 & 5 \\
\hline \multicolumn{9}{|l|}{ Person level } \\
\hline 1. Trait mindfulness & .84 & & 3.70 & 0.49 & $-.35^{* * *}$ & $.56^{* * *}$ & .12 & $-.19^{* *}$ \\
\hline \multicolumn{9}{|l|}{ Day level } \\
\hline 2. Surface acting & .72 & .47 & 2.11 & 0.70 & & & & \\
\hline 3. State mindfulness & .77 & .62 & 3.87 & 0.61 & $-.47^{* *}$ & & & \\
\hline 4. Job satisfaction & & .60 & 3.76 & 0.83 & $-.27^{* *}$ & $.25^{* * *}$ & & \\
\hline 5. Emotional exhaustion & & .49 & 2.18 & 0.91 & $.37^{* * *}$ & $-.34^{* * *}$ & $-.25^{\text {*** }}$ & \\
\hline
\end{tabular}

Note. Below the diagonal, correlations at the day level are displayed $(n=1,071-1,083)$; above the diagonal, correlations at the person level averaged across the 5 days are displayed $(n=217-219)$. For variables assessed at the day level, Cronbach's $\alpha$ was calculated individually for every day, and then the respective five reliabilities were averaged. ICC $=$ intraclass correlation coefficient.

${ }^{*} p<.05$ (two-tailed). ${ }^{* * *} p<.01$ (two-tailed). 
Job satisfaction. In the evening, participants indicated their momentary level of job satisfaction with a one-item measure that has been developed to assess job satisfaction in event-sampling studies (Bono, Foldes, Vinson, \& Muros, 2007; see also Beckers et al., 2008): "At this moment, I am fairly satisfied with my job."

Emotional exhaustion. The burnout dimension of emotional exhaustion (Maslach \& Jackson, 1981) was assessed in the evening by asking participants to indicate to what extent they "felt emotionally drained." This measure has previously been used in a number of diary- and event-sampling studies (Teuchmann, Totterdell, \& Parker, 1999; Totterdell \& Holman, 2003) to measure emotional exhaustion.

Analyses. Given the hierarchical data structure (daily reports nested in persons), hypotheses were tested with multilevel structural equation modeling (MSEM) using Mplus, Version 5.21 (Muthén \& Muthén, 2007) and following Preacher and colleagues' recommendations for testing multilevel mediation (Preacher, Zhang, \& Zyphur, 2011; Preacher, Zyphur, \& Zhang, 2010). Unlike traditional multilevel models that combine within- and between-person effects in one single slope, one of the advantages of this approach is that it decomposes the variance of Level 1 variables (day level) into within and between components and thereby accounts for the fact that relationships might differ between the between- and the within-person levels. In consequence, using daily mindfulness (dM), analyses reveal information on (a) the effect of daily variations from a person's mean level of mindfulness on, for example, job satisfaction (within-person; state component); (b) the effect of a person's mean level of mindfulness on, for example, job satisfaction (between-person; trait component); and (c) the extent to which this relationship is mediated by surface acting on the within- and the between-person levels, respectively. How the mediated relation between $\mathrm{dM}$ and the outcome variables is modeled on the within- and the between-person levels is illustrated in Figure 1. This corresponds to a 1-1-1 design where predictor, mediator, and outcome variables are all assessed at Level 1, the day level (Preacher et al., 2010).

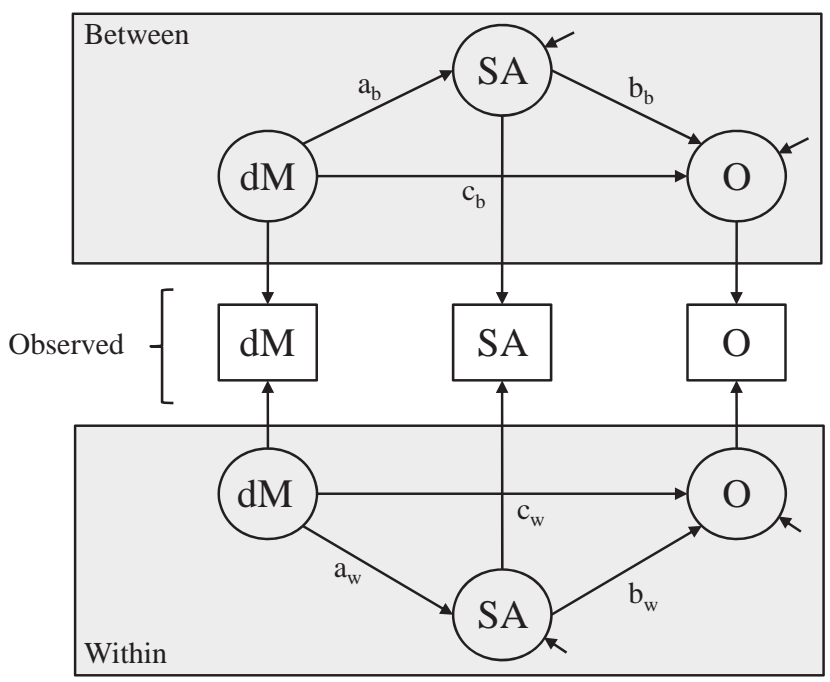

Figure 1. Multilevel structural equation model showing a 1-1-1 multilevel mediation model between day-level (state) mindfulness (dM), surface acting (SA), and an outcome variable (O; i.e., emotional exhaustion or job satisfaction). Figure is based on Preacher et al. (2011).
One might argue that the between-person component of mindfulness assessed on a daily basis (dM) differs from traditional assessments of trait mindfulness where participants indicate at one point in time how they generally behave and feel. To replicate findings regarding between-person effects of mindfulness from the 1-1-1 model, we therefore used a traditional measure of trait mindfulness in the general survey and tested a 2-1-1 mediation model, with trait mindfulness (tM) as a Level 2 (person level) predictor and surface acting and the outcome variables assessed at Level 1 (see Figure 2).

Variance decomposition. Before starting to test hypotheses, we inspected the relative amount of variance in study variables lying between- and within-persons by inspecting the ICC1 based on an unconditional random coefficient model (Bliese, 2006; Bliese \& Ployhart, 2002; Hox, 2002). Results are indicated in Table 1. Mindfulness displayed an ICC1 of .62, indicating that $62 \%$ of the variance in mindfulness was between-person variation, while $38 \%$ lay within persons. This suggests that mindfulness can indeed be conceptualized as a trait and a state construct and that it is appropriate to use multilevel modeling.

\section{Results}

Means, standard deviations, and intercorrelations between study variables are displayed in Table 1 . Table 2 shows results of a multilevel analysis investigating direct relationships between mindfulness and emotional exhaustion/job satisfaction. On the within- and between-person levels, daily mindfulness displayed significant relationships with emotional exhaustion and job satisfaction as did trait mindfulness. These relationships were significant when applying a conservative two-tailed test of significance. The relationship of trait mindfulness with job satisfaction was somewhat weaker but still significant when using a one-tailed test of significance, which is suitable when testing a directional hypothesis. Hypotheses $1 \mathrm{a}$ and $1 \mathrm{~b}$ and Hypotheses $2 \mathrm{a}$ and $2 \mathrm{~b}$ were thus fully supported. Table 3 further reveals significant indirect effects of mindfulness on emotional exhaustion and job satisfaction through surface acting, (a) when using daily mindfulness as a predictor on the within- and between-person levels in a 1-1-1 multilevel mediation model and (b) when using trait mindfulness as a predictor in a 2-1-1 mediation model. Surface acting consequently mediated the relationship of mindfulness with job satisfaction and emotional exhaustion on the between- and on the within-person level, supporting Hypotheses $3 \mathrm{a}$ and $3 \mathrm{~b}$ and Hypotheses $4 \mathrm{a}$ and $4 \mathrm{~b}$.

\section{Brief Discussion of Study 1}

Study 1 confirmed that state and trait mindfulness are related to emotional exhaustion and job satisfaction on a daily basis and that the relationships are mediated by surface acting.

Study 1 was a diary study spanning across 5 work days, and mindfulness and surface acting were assessed at different time points (after work) than dependent variables (in the evening). Nevertheless, analyses of these kinds of diary studies focus on within-day relationships between variables and they are consequently cross-sectional in nature. Causal inferences can therefore not be drawn and it remains unclear whether mindfulness truly leads to a reduction in surface acting, emotional exhaustion, and 


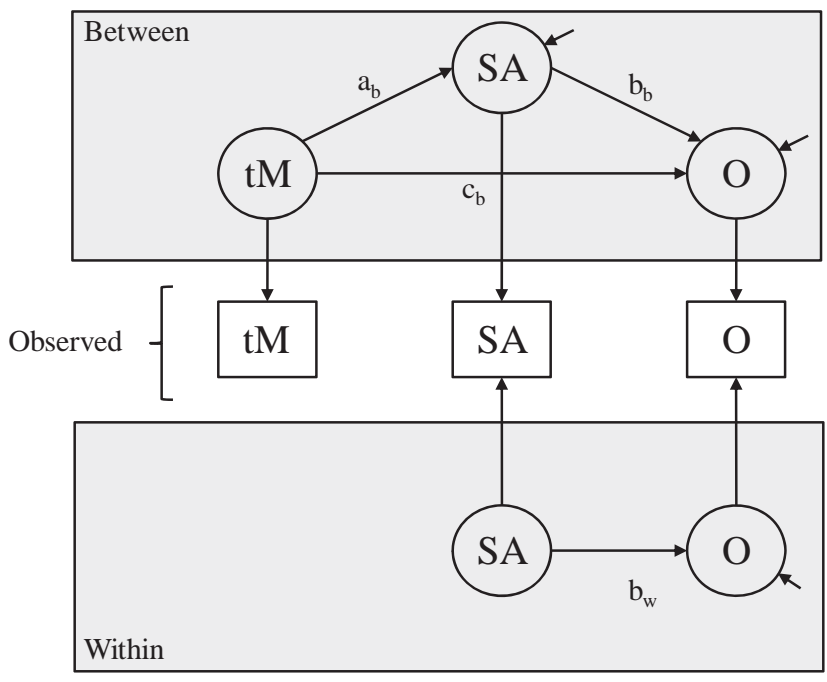

Figure 2. Multilevel structural equation model showing a 2-1-1 multilevel mediation model between trait mindfulness (tM), surface acting (SA), and an outcome variable (O; i.e., emotional exhaustion or job satisfaction). Figure is based on Preacher et al. (2011).

job satisfaction as suggested by the literature reviewed above. An alternative explanation of the relationships found in Study 1 may be that surface acting is a stressful experience that results in a reduction of mindfulness. Similarly, employees experiencing emotional exhaustion and reduced job satisfaction may be less motivated or capable of being attentive to the present moment with a nonjudgmental attitude. Fredrickson, Cohn, Coffey, Peik, and Finkel's (2008) findings that positive emotions help build consequential personal resources including mindful attention suggest that directions of effects may also be reversed.

\section{Study 2}

To investigate whether mindfulness is the causal agent and precedes surface acting and emotional exhaustion/job satisfaction, goal of Study 2 was to conduct an experimental field study with a control group (CG) and a mindfulness intervention group (MIG), receiving a mindfulness self-training intervention. Apart from the mindfulness intervention, the set-up of the study was equivalent to
Study 1 , a daily diary study extending over 10 rather than 5 work days. To the extent that participants in the MIG display lower levels of surface acting and emotional exhaustion and higher levels of job satisfaction than the CG, one may infer that mindfulness actually leads to more surface acting, emotional exhaustion, and job satisfaction.

The mindfulness self-training intervention was based on two closely linked mindfulness programs - namely, mindfulness-based cognitive therapy (MBCT; Segal et al., 2002) and mindfulnessbased stress reduction (MBSR; Kabat-Zinn, 1982), both consisting of (a) mindfulness meditation and (b) informal daily exercises. Mindfulness meditation is a specific form of meditation. Although different approaches to meditation bear similarities and some even argue that they might not exist in a pure form, the literature has differentiated meditation techniques by the type of attention that is cultivated (concentration vs. awareness) and the cognitive processes involved (e.g., simply observing emotions vs. deliberately modifying them; Sedlmeier et al., 2012). A frequently used differentiation is that between concentrative techniques (e.g., transcendental meditation) and mindfulness techniques (Kristeller \& Rikhye, 2008; Sedlmeier et al., 2012). In concentrative techniques, meditators turn their attention to an object like a mantra, picture, breath, or physical experience and learn to disengage from thoughts and emotions attempting to experience deep rest and comfort (Sedlmeier et al., 2012). Mindfulness meditation places emphasis on staying present in the current moment and promoting a state of awareness in an alert, nonjudgmental way. Goal is to learn to observe and become aware of thoughts and emotions without getting caught up in chains of associations and without reacting upon them. The primary aim of mindfulness is not to experience rest or comfort, but to learn to observe thoughts and feelings and to cope with discomfort by means of acceptance and compassion. "The mind of a highly experienced meditator should observe just thoughts, just feelings, or just sensations (without letting thoughts create emotions, and these emotions other thoughts, etc.)" (Sedlmeier et al., 2012, p. 1141). In addition to formal meditation practice (e.g., sitting on a cushion), mindfulness practice involves daily awareness of automatic habitual patterns of thinking, reacting, and feeling. As a unique feature, mindfulnessbased interventions therefore involve both formal meditation exercises and daily awareness exercises.

Table 2

Multi-Level Models Predicting Daily Emotional Exhaustion and Job Satisfaction From State and Trait Mindfulness in Study 1

\begin{tabular}{|c|c|c|c|c|c|c|c|c|}
\hline \multirow[b]{3}{*}{ Parameter } & \multicolumn{4}{|c|}{ Daily mindfulness $(\mathrm{dM})$ as predictor } & \multicolumn{4}{|c|}{ Trait mindfulness (tM) as predictor } \\
\hline & \multicolumn{2}{|c|}{ Emotional exhaustion } & \multicolumn{2}{|c|}{ Job satisfaction } & \multicolumn{2}{|c|}{ Emotional exhaustion } & \multicolumn{2}{|c|}{ Job satisfaction } \\
\hline & Estimate & $S E$ & Estimate & $S E$ & Estimate & $S E$ & Estimate & $S E$ \\
\hline \multicolumn{9}{|l|}{ Between level } \\
\hline Intercept & $2.183^{* *}$ & 0.044 & $3.766^{* *}$ & 0.044 & $2.178^{* * *}$ & 0.047 & $3.769^{* * *}$ & 0.046 \\
\hline Mindfulness & $-0.575^{* *}$ & 0.093 & $0.480^{* *}$ & 0.097 & $-0.275^{*}$ & 0.108 & $0.157^{\dagger}$ & 0.096 \\
\hline Residual variance & $0.333^{* *}$ & 0.046 & $0.359^{* *}$ & 0.044 & $0.384^{* * *}$ & 0.055 & $0.406^{* *}$ & 0.049 \\
\hline \multicolumn{9}{|l|}{ Within level } \\
\hline Mindfulness & $-0.405^{* *}$ & 0.096 & $0.133^{*}$ & 0.058 & & & & \\
\hline Residual variance & $0.400^{* *}$ & 0.035 & $0.274^{* *}$ & 0.030 & $0.423^{* *}$ & 0.040 & $0.275^{* *}$ & 0.031 \\
\hline
\end{tabular}

Note. Models are random intercept models; $n=217-219$ at the person level. Average number of observations per person $=4.94-4.96$.

${ }^{\dagger} p<.05$ (one-tailed). ${ }^{*} p<.05$ (two-tailed). ${ }^{* * *} p<.01$ (two-tailed). 
Table 3

Multi-Level Mediation Models Predicting Daily Emotional Exhaustion and Job Satisfaction From Mindfulness and Surface Acting in Study 1

\begin{tabular}{|c|c|c|c|c|c|c|c|c|}
\hline \multirow[b]{3}{*}{ Parameter } & \multicolumn{4}{|c|}{$1-1-1$ mediation models ( $\mathrm{dM}$ as predictor) } & \multicolumn{4}{|c|}{ 2-1-1 mediation models (tM as predictor) } \\
\hline & \multicolumn{2}{|c|}{ Emotional exhaustion } & \multicolumn{2}{|c|}{ Job satisfaction } & \multicolumn{2}{|c|}{ Emotional exhaustion } & \multicolumn{2}{|c|}{ Job satisfaction } \\
\hline & Estimate & $S E$ & Estimate & $S E$ & Estimate & $S E$ & Estimate & $S E$ \\
\hline \multicolumn{9}{|l|}{ Between level } \\
\hline Intercept & $2.183^{* *}$ & 0.041 & $3.766^{* *}$ & 0.043 & $2.178^{* *}$ & 0.042 & $3.770^{* * *}$ & 0.044 \\
\hline Path $a_{b}$ & $-0.588^{* *}$ & 0.087 & $-0.592^{* *}$ & 0.084 & $-0.371^{* *}$ & 0.081 & $-0.369^{* *}$ & 0.081 \\
\hline Path $b_{b}$ & $0.531^{* *}$ & 0.136 & $-0.376^{* *}$ & 0.127 & $0.659^{* *}$ & 0.121 & $-0.530^{* *}$ & 0.106 \\
\hline Path $c_{b}$ & $-0.262^{*}$ & 0.116 & $0.259^{*}$ & 0.120 & -0.034 & 0.103 & -0.044 & 0.090 \\
\hline Indirect effect & $-0.312^{* *}$ & 0.088 & $0.223^{* *}$ & 0.073 & $-0.245^{* *}$ & 0.067 & $0.195^{* *}$ & 0.053 \\
\hline Residual variance outcome & $0.289^{* *}$ & 0.044 & $0.338^{* *}$ & 0.042 & $0.298^{* *}$ & 0.047 & $0.349^{* *}$ & 0.043 \\
\hline Residual variance surface acting & $0.153^{* *}$ & 0.023 & $0.149^{* *}$ & 0.021 & $0.198^{* *}$ & 0.028 & $0.198^{* *}$ & 0.028 \\
\hline \multicolumn{9}{|l|}{ Within level } \\
\hline Path $\mathrm{a}_{\mathrm{w}}$ & $-0.457^{* *}$ & 0.058 & $-0.466^{* *}$ & 0.057 & & & & \\
\hline Path $b_{w}$ & $0.208^{* *}$ & 0.069 & $-0.117^{*}$ & 0.047 & $0.285^{* *}$ & 0.063 & $-0.136^{* *}$ & 0.043 \\
\hline Path $c_{\mathrm{w}}$ & $-0.310^{* *}$ & 0.104 & 0.077 & 0.063 & & & & \\
\hline Indirect effect & $-0.095^{* * *}$ & 0.035 & $0.055^{*}$ & 0.022 & & & & \\
\hline Residual variance outcome & $0.390^{* *}$ & 0.034 & $0.271^{* *}$ & 0.031 & $0.402^{* *}$ & 0.037 & $0.268^{* * *}$ & 0.030 \\
\hline Residual variance surface acting & $0.233^{* *}$ & 0.025 & $0.234^{* *}$ & 0.025 & & & & \\
\hline
\end{tabular}

Note. Models are random intercept models; $n=217-219$ at the person level. Average number of observations per person $=4.94-4.96$. $\mathrm{dM}=\mathrm{daily}$ mindfulness; $\mathrm{tM}=$ trait mindfulness. The paths refer to Figures 1 and 2. Path $\mathrm{a}_{\mathrm{b}} / \mathrm{a}_{\mathrm{w}}=$ mindfulness $\rightarrow$ surface acting; Path $\mathrm{b}_{\mathrm{b}} / \mathrm{b}_{\mathrm{w}}=$ surface acting $\rightarrow$ outcome variable; Path $\mathrm{c}_{\mathrm{b}} / \mathrm{c}_{\mathrm{w}}=$ mindfulness $\rightarrow$ outcome variable.

${ }^{*} p<.05$ (two-tailed). ${ }^{* * *} p<.01$ (two-tailed).

\section{Method}

Sample. To recruit participants, employees holding a broad range of jobs were approached individually in, for example, hospitals, schools, kindergartens, medical practices in Berlin and various cities in North Rhine-Westphalia, Germany, and were invited to participate in the study. In line with similar studies (Fredrickson et al., 2008), they received a flyer describing the project as a scientific study investigating the benefits of mindfulness meditation and including practical information such as length of the study and confidentiality. No monetary compensation for study participation was offered. A total of 203 participants enrolled in the study. On a random basis, 102 participants were assigned to the MIG and 101 to the waitlist control group (CG). In the following they received a package containing a general questionnaire, the diary booklet, and-in case of the MIG-mindfulness meditation instructions and material. A total of 102 participants dropped out of the study and failed to return diaries in time, resulting in a sample of 101 participants (overall response rate of $49.8 \%$ ). This response rate is close to the average response rate $(52.3 \%)$ reported in a recent meta-analysis on response rates in organizational survey research (Anseel et al., 2010). With 50 participants remaining in the MIG and 51 in the CG, the response rate did not differ between the treatment and the control groups (49.5\% MIG, 50.5\% CG). This finding suggests that the dropout was independent of the intervention. A total of 37 participants were excluded from analyses: Six participants stopped filling in their diaries, 12 participants did not hold interactive service jobs or failed to indicate their job, and 19 participants assigned to the MIG did not comply with the mindfulness meditation instructions and meditated less than $6 \mathrm{~min}$ per day on average. A multivariate analysis of variance testing for potential differences regarding age, tenure, trait mindfulness, trait surface acting, trait job satisfaction, and trait emotional exhaustion revealed no significant differences between compliant and non-compliant participants within the MIG: $F(12,48)=0.41, n s$. A chi-square test further revealed no significant gender differences between compliant and noncompliant participants in the MIG, $\chi^{2}(1)=3.2, n s$. The final sample comprised 64 participants, 22 in the MIG and 42 in the CG. Participants (18 men, 46 women) had a mean age of 38.6 years ( $S D$ $=11.1)$, and an average organizational tenure of 9 years $(S D=$ 8.6). The sample consisted of teachers $(17.2 \%)$, social workers/ social pedagogues $(15.6 \%)$, kindergarten teachers $(7.8 \%)$, physicians $(7.8 \%)$, waiters/hotel service employees $(6.3 \%)$, industrial clerks, bankers, medical assistants (4.7\%, respectively), nurses, psychologists, retail salesmen, pharmacists (3.1\%, respectively), and other interactive service jobs (18.8\%).

Procedure. Both groups (CG and MIG) received a diary booklet containing a general survey assessing demographic information and baseline measures. They were asked to fill in this general survey before starting with the diary covering 10 work days. Each day, participants were asked to fill in their diary after work. Participants in the MIG received the intervention described below, while the waitlist-CG received no intervention and just filled in the diary. After completion of the study, they received a booklet containing the same self-training intervention as the MIG.

The mindfulness self-training intervention. For the MIG, a mindfulness self-training approach was used consisting of different standardized exercises of MBCT (Segal et al., 2002) and MBSR (Kabat-Zinn, 1982). These are training programs in which participants learn to become aware of thoughts and feelings and are taught to observe them through the repeated practice of intentionally returning attention to an object (e.g., the breath or body sensations). MBCT and MBSR consist of guided mindfulness meditation and informal daily exercises both aiming to cultivate an 
accepting, nonjudgmental attitude to what one experiences in each moment. Whereas mindfulness programs like MBCT and MBSR span over 8 weeks and involve regular group-training sessions with a mindfulness trainer, the present intervention was based on a self-training approach, spanned over 2 weeks (10 working days) and focused on some key mindfulness practices that were relatively brief and could be readily integrated into participants' daily (work-) life. The following exercises of the MBCT and the MBSR protocol were employed: the BodyScan, the Three-Minute Breathing Space, the Daily Routine Activities, and the Raisin Exercise. In order to further cultivate a compassionate mindset, which is considered an essential aspect of mindfulness practice (e.g., Kuan, 2008; Sanharakshita, 2004; Shapiro \& Carlson, 2009; Siegel, 2010), a Loving Kindness Meditation was added to the intervention. Essential to all of these mindfulness practices is developing an open and compassionate mindset. Instead of criticizing or blaming oneself, for instance because one gets distracted during the exercises, the program teaches to be kind toward oneself.

To familiarize participants with mindful attention and awareness, they conducted the Raisin Exercise (eating with awareness) and the Body Scan on the first training day (M. Williams, Teasdale, Segal, \& Kabat-Zinn, 2007). The BodyScan is a formal meditation practice, where bodily sensations are used as an anchor for attention. In this exercise, awareness of the body and the observing of distracting thoughts are trained. Second, we introduced the Three-Minute Breathing Space (Siegel, 2010; M. Williams et al., 2007) as a cornerstone of our mindfulness intervention. It is an exercise that helps to (re)connect with the present moment. It aims at training awareness of thoughts, feelings, and bodily sensations by paying attention to them. It has specifically been designed to be applicable in everyday live (M. Williams et al., 2007). Participants were asked to follow this meditation at a minimum twice a day, every morning and evening throughout the study. In the morning of Day 4, participants received instructions to practice being fully aware during daily routine activities. To bring mindfulness to their everyday life, they were asked to choose at least one routine activity (e.g., taking a shower, driving to work, drinking coffee) and try to conduct it in a mindful way, bringing full awareness and attention to it. Lastly, a Loving-Kindness Meditation was introduced on the evening of Day 4. It cultivates caring, kindness, and love for the meditator him-/herself and others (Shapiro \& Carlson, 2009). It starts with an initial focus on the breath and then directs warm, compassionate, and tender feelings to oneself and subsequently to others, including loved ones, neutral persons, and difficult persons. It teaches mindful attitudes of acceptance, compassion for oneself and for others which is particularly important for employees working in the helping professions (Shapiro \& Carlson, 2009) but also in other interactive service jobs where employees need to respond to the needs of others and face emotionally demanding situations. Participants were asked to conduct the Loving-Kindness Meditation every day.

These mindfulness exercises were presented in written format. A general introduction to mindfulness and mindfulness meditation, description of the mindfulness meditation practices and detailed instructions on how and when to conduct these practices were incorporated in the diary booklet starting on Day 2. Moreover, participants received a CD containing audio-files of the guided meditations. In addition, participants received a postcard with a citation from Thich Nhat Hanh which they were asked to put up in a place where it reminds them of their daily meditation practice. To further remind and inspire them to engage in daily meditation practice, mindfulness-related citations from mindfulness scholars like Eckhart Tolle or Thich Nhat Hanh were provided in the diary booklet from Day 4 to Day 10. Lastly, participants received daily e-mails with additional mindfulness-related citations.

Measures. Data collection consisted of a general survey and a diary booklet. The general survey was completed once before participants started to fill in the diary booklet. It assessed demographic variables, trait mindfulness, and general levels of surface acting, emotional exhaustion, and job satisfaction as baseline measures. Items were answered on 5-point rating scales. Cronbach's alphas are depicted in Table 4.

Trait mindfulness. For trait mindfulness, the MAAS was used as in Study 1.

Surface acting. General levels of surface acting were assessed with four items: three items from Brotheridge and Lee's (2002) Emotional Labor Scale and one item ("Show emotions that are expected rather than what I feel") from Lee and Brotheridge (2011) to assess the hiding and faking sub-aspect of surface acting with two items each.

Table 4

Intercorrelations Between Study Variables of Study 2

\begin{tabular}{|c|c|c|c|c|c|c|c|c|c|c|c|c|}
\hline Variable & Cronbach's $\alpha$ & $\mathrm{ICC}_{1}$ & $M$ & $S D$ & 2 & 3 & 4 & 5 & 6 & 7 & 8 & 9 \\
\hline \multicolumn{13}{|l|}{ Person level } \\
\hline 1. Trait mindfulness & .83 & & 3.54 & 0.58 & -.23 & $-.49^{* * *}$ & .20 & .04 & $.56^{* *}$ & $-.28^{*}$ & $-.36^{* *}$ & .04 \\
\hline 2. Trait surface acting & .62 & & 2.54 & 0.65 & & $.35^{* *}$ & -.16 & -.14 & $-.26^{*}$ & $.37^{* * *}$ & $.31^{*}$ & -.21 \\
\hline 3. Trait emotional exhaustion & .77 & & 1.99 & 0.58 & & & $-.46^{* *}$ & .15 & $-.27^{*}$ & .17 & $.49^{* *}$ & $-.27^{*}$ \\
\hline 4. Trait job satisfaction & .81 & & 3.98 & 0.77 & & & & .07 & .21 & -.07 & $-.30^{*}$ & $.58^{* *}$ \\
\hline 5. Average meditation time & & & 3.17 & 4.57 & & & & & .24 & $-.38^{* *}$ & -.18 & $.25^{*}$ \\
\hline \multicolumn{13}{|l|}{ Day level } \\
\hline 6. State mindfulness & .88 & .66 & 3.86 & 0.91 & & & & & & $-.62^{* *}$ & $-.58^{* *}$ & $.33^{*}$ \\
\hline 7. Surface acting & .88 & .50 & 2.16 & 0.97 & & & & & $-.55^{* *}$ & & $.49^{* *}$ & -.24 \\
\hline 8. Emotional exhaustion & .82 & .54 & 2.03 & 0.99 & & & & & $-.52^{* * *}$ & $.44^{* *}$ & & $-.45^{\text {*** }}$ \\
\hline 9. Job satisfaction & & .37 & 3.42 & 1.05 & & & & & $.27^{* * *}$ & $-.23^{* *}$ & $-.39^{* *}$ & \\
\hline
\end{tabular}

Note. Below the diagonal, correlations at the day level are displayed $(N=384)$; above the diagonal, correlations at the person level averaged across the 5 days are displayed $(N=64)$. For variables assessed at the day level, Cronbach's $\alpha$ was calculated individually for every day, and then the average of the respective five reliabilities was taken. ICC $=$ intraclass correlation coefficient.

${ }^{*} p<.05$ (two-tailed). ${ }^{* *} p<.01$ (two-tailed). 
Table 5

Multi-Level Models Predicting Daily Mindfulness, Emotional Exhaustion, and Job Satisfaction From Group Membership in Study 2

\begin{tabular}{|c|c|c|c|c|c|c|}
\hline \multirow[b]{2}{*}{ Parameter } & \multicolumn{2}{|c|}{ Mindfulness } & \multicolumn{2}{|c|}{ Emotional exhaustion } & \multicolumn{2}{|c|}{ Job satisfaction } \\
\hline & Estimate & $S E$ & Estimate & $S E$ & Estimate & $S E$ \\
\hline \multicolumn{7}{|l|}{ Between level } \\
\hline Intercept & $3.86^{* * *}$ & 0.077 & $2.030^{* *}$ & 0.080 & $3.422^{* * *}$ & 0.070 \\
\hline Condition & $0.328^{*}$ & 0.161 & $-0.428^{* *}$ & 0.169 & $0.342^{*}$ & 0.147 \\
\hline Outcome at baseline $\mathrm{e}^{\mathrm{a}}$ & $0.729^{* * * *}$ & 0.132 & $0.705^{* *}$ & 0.140 & $0.535^{* *}$ & 0.092 \\
\hline Residual variance & $0.330^{* *}$ & 0.067 & $0.336^{* *}$ & 0.073 & $0.197^{* * *}$ & 0.057 \\
\hline \multicolumn{7}{|l|}{ Within level } \\
\hline Residual variance & $0.286^{* * *}$ & 0.023 & $0.458^{* *}$ & 0.036 & $0.702^{* * *}$ & 0.056 \\
\hline
\end{tabular}

Note. Models are random intercept models; $N=64$ at the person level. Average number of observations per person $=5.92-5.94$. Condition was coded $0=$ control group, $1=$ experimental group.

${ }^{a}$ Outcome at baseline was trait mindfulness/trait emotional exhaustion/trait job satisfaction.

$* p<.05$ (two-tailed). ${ }^{* * *} p<.01$ (two-tailed).

Emotional exhaustion. The nine respective items of the Maslach Burnout Inventory (MBI) were used (Büssing \& Perrar, 1992; Maslach \& Jackson, 1984).

Job satisfaction. Job satisfaction was assessed with five items from Judge, Locke, Durham, and Kluger (1998).

Furthermore, state mindfulness, surface acting, emotional exhaustion and job satisfaction were assessed on a daily basis, after work.

Mindfulness. The state MAAS was used as in Study 1.

Surface acting. The four items used in the general survey were adapted to the day level by asking participants to indicate to what extent these items applied to them during their work day.

Job satisfaction. The same item as in Study 1 was used.

Table 6

Multi-Level Mediation Models (2-1-1) Predicting Daily Emotional Exhaustion and Job Satisfaction From Group Membership and Daily Surface Acting in Study 2

\begin{tabular}{|c|c|c|c|c|}
\hline \multirow[b]{2}{*}{ Parameter } & \multicolumn{2}{|c|}{$\begin{array}{l}\text { Emotional } \\
\text { exhaustion }\end{array}$} & \multicolumn{2}{|c|}{ Job satisfaction } \\
\hline & Estimate & $S E$ & Estimate & $S E$ \\
\hline \multicolumn{5}{|l|}{ Between level } \\
\hline Intercept & $2.033^{* *}$ & 0.073 & $3.430^{* * *}$ & 0.069 \\
\hline Path $a_{b}$ & $-0.545^{* *}$ & 0.182 & $-0.545^{* *}$ & 0.182 \\
\hline Path $b_{b}$ & $0.388^{* *}$ & 0.127 & -0.119 & 0.119 \\
\hline Path $c_{b}$ & -0.206 & 0.169 & $0.270^{\dagger}$ & 0.158 \\
\hline Path Baseline $\rightarrow$ Outcome $\mathrm{e}^{\mathrm{a}}$ & $0.597^{* * *}$ & 0.128 & $0.518^{* *}$ & 0.090 \\
\hline Indirect effect & $-0.212^{*}$ & 0.099 & 0.065 & 0.068 \\
\hline Residual variance outcome & $0.278^{* * *}$ & 0.061 & $0.187^{* * *}$ & 0.054 \\
\hline $\begin{array}{l}\text { Residual variance surface } \\
\text { acting }\end{array}$ & $0.405^{* *}$ & 0.086 & $0.405^{* *}$ & 0.086 \\
\hline \multicolumn{5}{|l|}{ Within level } \\
\hline Path $b_{w}$ & $0.353^{* *}$ & 0.051 & $-0.248^{* *}$ & 0.066 \\
\hline Residual variance outcome & $0.399^{* *}$ & 0.032 & $0.671^{* *}$ & 0.053 \\
\hline
\end{tabular}

Note. Models are random intercept models; $N=64$ at the person level. Average number of observations per person $=5.92$. The paths refer to Figure 2. Path $a_{b}=$ condition $\rightarrow$ surface acting; Path $b_{b}=$ surface acting $\rightarrow$ outcome variable; Path $\mathrm{c}_{\mathrm{b}}=$ condition $\rightarrow$ outcome variable. Condition was coded $0=$ control group, $1=$ experimental group.

${ }^{a}$ The path Baseline-Outcome depicts the link between the baseline measurement of trait emotional exhaustion/job satisfaction and the respective outcome variable.

${ }^{\dagger} p<.05$ (one-tailed). ${ }^{*} p<.05$ (two-tailed). ${ }^{* *} p<.01$ (two-tailed).
Emotional exhaustion. To assess emotional exhaustion after work, we used three items of the respective MBI scale that was used in the general survey and asked participants how they currently feel. Sample items are "I feel emotionally drained," and "I feel burnt out."

Meditation time per day. To assess compliance with the treatment, participants in the experimental condition were asked every evening to indicate how many minutes they dedicated to their meditation practice in the morning and in the evening.

Analyses. As in Study 1, we had a hierarchical data structure (daily reports nested in persons) and therefore tested hypotheses with MSEM using Mplus, Version 5.21 (Muthén \& Muthén, 2007). Multilevel mediation analyses were conducted following Preacher and colleagues' recommendations (Preacher et al., 2011, 2010). As described in the Method section, the intervention consisted of various mindfulness meditation practices that were gradually introduced in the training phase of the study, with the last practice (Loving-Kindness Meditation) being introduced on the evening of Day 4. To investigate effects of the intervention as a whole, analyses are based on data from the assessment phase of the study ranging from Day 5 to Day 10.

\section{Results}

Means, standard deviations, intercorrelations and ICC1s for all study variables are depicted in Table 4. As a manipulation check, we first analyzed whether the experimental manipulation had an effect on daily levels of mindfulness (see Table 5). A multilevel model using condition as a person-level predictor of daily mindfulness and controlling for baseline levels of trait mindfulness confirmed that participants in the MIG had significantly higher levels of daily mindfulness compared to participants in the CG. Similarly, condition was a significant predictor of emotional exhaustion and job satisfaction, confirming Hypotheses 1c and 2c. Finally, we tested multilevel mediation models (2-1-1) where daily surface acting mediated the relationship of condition with daily emotional exhaustion and job satisfaction (see Table 6). To control for pre-intervention differences in dependent variables between the MIG and the CG, we controlled for baseline levels of emotional exhaustion and job satisfaction. Results revealed a significant indirect path via surface acting for emotional exhaustion but not for job satisfaction. A close inspection of Tables 5 and 6 
reveals that the missing indirect effect for job satisfaction was due to a missing link between daily surface acting and job satisfaction (Path b) while the effect of condition on surface acting and job satisfaction was significant. Hypothesis $4 \mathrm{c}$ was thus confirmed, while Hypothesis $3 \mathrm{c}$ was not. ${ }^{1}$

\section{Brief Discussion of Study 2}

Study 2 largely confirmed findings of Study 1 with the exception of the missing mediation for job satisfaction which may be due to the relatively lower power of Study 2. Given the experimental set-up of the study, findings suggest that decreases in surface acting, emotional exhaustion and increases in job satisfaction are causally driven by mindfulness meditation. Furthermore, our study helps clarifying the relationship between various conceptualizations of mindfulness. Researchers have used different conceptualizations of mindfulness including experimentally induced mindfulness, mindfulness-based treatment programs, and naturally occurring mindfulness in terms of trait and state mindfulness (Glomb et al., 2011). The literature has witnessed some debate as to whether these different operationalizations tab the same construct or whether natural variations in mindfulness measured with self-report measures capture something else than what is targeted by experimentally induced mindfulness or mindfulnessbased treatment programs following Buddhist traditions (Brown, Ryan, et al., 2011; Davidson, 2010). The present findings suggest that mindfulness-based meditation practices and naturally occurring trait and state mindfulness are closely interrelated and function similarly: Not only was our measure of state mindfulness significantly affected by the mindfulness intervention, we also found the same pattern of results for trait mindfulness, state mindfulness, and a mindfulness self-training intervention.

Study 2 is certainly not without limitations. One limitation is that we used a wait-list control design where the CG received no treatment in the period when the MIG received the treatment. The CG was not provided with the treatment until data collection had been completed. In contrast to an active control group which typically receives a different kind of treatment during the time when the treatment group receives the treatment of interest, a potential disadvantage of such a no-treatment control group is that extra attention might be drawn to the treatment, which might have introduced expectation biases.

\section{General Discussion}

Findings of Studies 1 and 2 suggest that for employees working in emotionally demanding jobs, mindfulness promotes job satisfaction and helps preventing burnout in terms of emotional exhaustion. Results showed that state and trait mindfulness are inversely related to employees' emotional exhaustion and positively related to their job satisfaction. The same relationships were found when mindfulness was induced by a self-training intervention, suggesting that the direction of effects is such that mindfulness precedes and affects emotional exhaustion and job satisfaction. Since our findings do not exclude the existence of reverse causation, it is important to note, that effects may in fact be bidirectional. Mindfulness may decrease emotional exhaustion and increase job satisfaction and set free resources that may, in turn, lead to even higher levels of mindfulness creating a positive upward spiral (Fredrickson et al., 2008). Future research my thus investigate potential recursive effects between mindfulness and these constructs.

We argued that surface acting mediates the relationship between mindfulness and employee-well-being, implying not only that mindfulness precedes surface acting and emotional exhaustion/job satisfaction but also that surface acting precedes emotional exhaustion and job satisfaction. While Study 2 confirmed that mindfulness affects surface acting, emotional exhaustion, and job satisfaction, our findings do not allow to conclude that surface acting also precedes emotional exhaustion and job satisfaction. Longitudinal studies in the emotional labor literature have, however, suggested that the direction of effects is such that surface acting (or a sub-aspect of it) precedes increased psychological distress and job satisfaction (Côté \& Morgan, 2002; Hülsheger et al., 2010). Hülsheger and colleagues explicitly tested for reverse causation. They conducted a two-wave longitudinal panel study, testing longitudinal lagged effects between surface acting and irritation (an indicator of psychological distress that is related to emotional exhaustion) using structural equation modeling (SEM), which is considered to be the most adequate method to analyze cross-lagged panel designs (Finkel, 1995; L. J. Williams \& Podsakoff, 1989). Results indicated that surface acting led to increases in subsequent strain, but not vice versa. To provide further insights into the directions of effects of surface acting with emotional exhaustion and job satisfaction on a daily basis, future research might consider assessing surface acting as well as emotional exhaustion and job satisfaction at several time points during one working day and perform cross-lagged analyses within days.

The present findings also contribute to the mindfulness literature by shedding light on a central mechanism underlying the salutary effects of mindfulness in the work-context. Researchers have long been speculating about the processes driving the beneficial effects of mindfulness and emotion and affect regulation has always been a cornerstone of it (Bishop et al., 2004; Glomb et al., 2011; Shapiro et al., 2006). By identifying surface acting as a mediator, our field studies add to the incipient body of experimental laboratory research focusing on the role of emotion regulation in the salubrious effects of mindfulness (Arch \& Craske, 2006; Erisman \& Roemer, 2010).

Overall, results of Study 1 and Study 2 revealed unanimously that mindfulness was more strongly related to emotional exhaus-

\footnotetext{
${ }^{1}$ As described in the Method section of Study 2, we removed noncompliant participants from the sample: Participants who were assigned to the experimental group but did not comply with the instructions and meditated less than 6 min per day on average were thus removed from the sample. Doing so, we lost 19 participants from the experimental condition. As a supplementary analysis we used the full sample of 83 participants (41 MIG, 42 CG) and used the average meditation time per day across the study in minutes as a predictor in the analyses. The average meditation time per day in the MIG ranged between $1.8 \mathrm{~min}$ and $13.4 \mathrm{~min}$, with a mean of $6.8 \mathrm{~min}(S D=3.3)$. The average meditation time of the control group was set as 0 . We then conducted the same set of analyses and found the same patterns of results: Average daily meditation time across the study as a between-person variable significantly predicted daily levels of mindfulness, emotional exhaustion, and job satisfaction. Furthermore multilevel mediation models (2-1-1) revealed that daily surface acting significantly mediated the relationship of average meditation time with daily emotional exhaustion but not with job satisfaction due to a missing link between daily surface acting and job satisfaction.
} 
tion than to job satisfaction, both when considering trait as well as state mindfulness. A potential explanation of this finding is that surface acting - which we identified as an important mediating mechanism-may have a stronger effect on burnout, especially emotional exhaustion, than on job satisfaction. Supporting this idea, the present data revealed that zero-order correlations of surface acting were lower with job satisfaction than with emotional exhaustion. This pattern of relationships is consistent with findings from a recent meta-analysis on emotional labor, revealing consistently stronger relationships of surface acting with emotional exhaustion than with job satisfaction (Hülsheger \& Schewe, 2011).

The present findings also add to the emotional labor literature. To date, the emotional labor literature has predominantly focused on unraveling the consequences of emotion regulation at work and researchers have repeatedly called for more research on how to diminish employees' use of surface acting and promote more healthy strategies to cope with emotional job demands (e.g., Grandey, 2003; Judge, Woolf, \& Hurst, 2009; Martínez-Iñigo, Totterdell, Alcover, \& Holman, 2007). The present findings suggest that mindfulness is a fruitful way to deal with emotional job demands. Future research may continue exploring to what extent mindfulness-based interventions prove useful in helping emotion workers cope with daily job demands.

Another distinctive feature of the present research, specifically Study 1, was the diary design allowing us to analyze state and trait aspects of naturally occurring mindfulness simultaneously and thereby adopting a multilevel perspective (Bliese \& Jex, 2002). With $62 \%$ of the variance lying between and $38 \%$ within persons, results confirmed what has been suggested in theoretical accounts on mindfulness (Bishop et al., 2004; Dane, 2011; Glomb et al., 2011) - namely, that individuals naturally vary in their stable disposition to be more or less mindful. Above and beyond these stable dispositions, however, there are daily fluctuations in individuals' levels of mindfulness. It has previously been argued that it may not be taken for granted that a given construct displays the same association with an outcome at different hierarchical levels of investigation (Enders \& Tofighi, 2007). Importantly, the present findings revealed that three different conceptualizations of mindfulness function similarly with regard to employee well-being: The disposition to be more mindful over time and across situations apparently bears similar relationships with employee well-being as do fluctuating levels of mindfulness and mindfulness induced by a brief mindfulness intervention.

\section{Limitations and Future Directions}

Focusing on the role of mindfulness for emotional exhaustion and job satisfaction, the present study addressed two important organizational outcomes that have received no attention in the mindfulness literature yet. The mindfulness literature outside IO psychology has provided a wealth of evidence that mindfulness is a very powerful trait/state that promotes mental and physical health for a broad range of individuals in different life situations. We therefore believe that the present findings on the salutary effects of mindfulness and the mediating role of surface acting extent to other indicators of employee well-being. Future research may test this notion using, for example, physiological indicators of well-being (e.g., cortisol levels) or investigate mindfulness as a means to promote recovery from work stress. Apart from well- being outcomes, performance outcomes are equally important in organizational research. Given extant experimental research showing that mindfulness training improves cognitive functioning (Chiesa, Calati, \& Serretti, 2011), it may thus be fruitful to examine the link of mindfulness with job performance in future research (see also Dane, 2011; Glomb et al., 2011).

Although our study findings are based on a sample including a broad range of jobs, it was limited to employees holding interactive service jobs. For this sample of employees in emotionally demanding occupations, we were able to show that mindfulness affects emotional exhaustion and job satisfaction and it does so via the emotion regulation strategy of surface acting. This finding is in line with Glomb et al.'s (2011) argumentation that the effects of mindfulness may be particularly strong in jobs that require emotion regulation. Future research may thus be warranted to investigate whether findings generalize to other jobs that are not emotional labor intensive.

In the present studies, we focused on the role of emotion regulation, specifically surface acting, as an important mediator of the relationship between mindfulness and job satisfaction/emotional exhaustion in interactive service work. Notably, however, the mindfulness literature suggests that emotion regulation is not the only mechanisms underlying the mindfulness-well-being relationship (Bishop et al., 2004; Glomb et al., 2011; Shapiro et al., 2006). Other mechanisms, such as the use of more adaptive coping strategies (Weinstein et al., 2009) or increased vitality and sleep quality (Allen \& Kiburz, 2012), have also been shown to play a role in the general mindfulness-well-being relationship. In addition, we mentioned processes that may specifically drive the relationship of mindfulness with job satisfaction and emotional exhaustion-namely, increased self-determination and positive and negative affect (for job satisfaction) and a reduction in ego depletion (for emotional exhaustion). In future research it may thus be interesting to extend our research and investigate these and other potential processes underlying the beneficial effects of mindfulness. As a starting point, we conducted a set of supplementary analyses using our data set of Study 1 containing data on positive and negative affect. Specifically, we tested whether positive and negative affect mediate the relationship between mindfulness and job satisfaction as suggested by affective events theory (see introduction). Results revealed some evidence for negative affect as a mediator at the within-person level. ${ }^{2}$

The present article as well as the current mindfulness literature has focused almost exclusively on positive outcomes of mindfulness. However, mindfulness may not always be functional and it may also bear negative consequences for organizations. Mindfulness promotes awareness of one's emotions, thoughts, and values and thereby promotes behavior that matches a person's needs and interests (Brown \& Ryan, 2003). To the extent that an employee's

\footnotetext{
${ }^{2}$ We conducted two supplementary analyses testing negative affect and positive affect as potential mediators in the mindfulness-job satisfaction relationship: With the Study 1 data set, we tested two separate 1-1-1 mediation models using negative affect and positive affect, respectively (both assessed in the evening), as mediators. Negative affect had a significant indirect effect at the within-person level $(.06, p<.05)$ but not at the between-person level $(.10, n s)$. Positive affect had no significant indirect effect on neither the between-person level $(.03, n s)$ nor the within-person level $(.01, n s)$
} 
personal needs and goals (e.g., spending more time with family, taking on less duties, taking it slower at work) do not coincide with organizational goals, mindfulness may foster behavior that runs counter to organizational interests (Glomb et al., 2011). Future research may investigate whether there is not only a bright but also a dark side to mindfulness and scrutinize under which circumstances negative consequences for individuals and/or organizations may appear.

We shed light on the link between trait/state mindfulness and a brief mindfulness-self-training intervention with employee emotional exhaustion and job satisfaction. Considering that in Study 2 beneficial effects of mindfulness on emotional exhaustion and job satisfaction already emerged within a 10-day self-training program, one may expect a typically 8 -week mindfulness training under the supervision of a trained professional to yield even stronger results. Together with extant research on the effectiveness of comprehensive mindfulness-based interventions for employee well-being (Cohen-Katz, Wiley, Capuano, Baker, \& Shapiro, 2005; Galantino, Baime, Maguire, Szapary, \& Farrar, 2005; Irving et al., 2009; Krasner et al., 2009; Wolever et al., 2012), our findings suggest that it may prove useful to promote the integration of mindfulness-based interventions into workplace health promotion programs. It is, however, important to consider that there already exist various workplace stress management trainings that typically focus on cognitive-behavioral and relaxation techniques and that have proven effective in reducing employee distress (for a meta-analysis, see Richardson \& Rothstein, 2008). Further research is consequently needed to evaluate the relative efficacy of mindfulness-based interventions compared to existing stress management trainings. Jain et al. (2007) took a first step in doing so and revealed that a mindfulness meditation intervention and a relaxation intervention had similar effects on distress, while the meditation intervention had unique effects in decreasing rumination, which, in turn, has been shown to play an important role for sleep quality and recovery from work stress (Querstret \& Cropley, 2012).

\section{References}

Alberts, H. J. E. M., Schneider, F., \& Martijn, C. (2012). Dealing efficiently with emotions: Acceptance-based coping with negative emotions requires fewer resources than suppression. Cognition \& Emotion, 26, 863-870.

Allen, T. D., \& Kiburz, K. M. (2012). Trait mindfulness and work-family balance among working parents: The mediating effects of vitality and sleep quality. Journal of Vocational Behavior, 80, 372-379. doi: 10.1016/j.jvb.2011.09.002

Anseel, F., Lievens, F., Scholleart, E., \& Choragwicka, B. (2010). Response rates in organizational science, 1995-2008: A meta-analytic review and guidelines for survey researchers. Journal of Business and Psychology, 25, 335-349. doi:10.1007/s10869-010-9157-6

Arch, J. J., \& Craske, M. G. (2006). Mechanisms of mindfulness: Emotion regulation following a focused breathing induction. Behaviour Research and Therapy, 44, 1849-1858. doi:10.1016/j.brat.2005.12.007

Baer, R. A., Smith, G. T., Hopkins, J., Krietemeyer, J., \& Toney, L. (2006). Using self-report assessment methods to explore facets of mindfulness. Assessment, 13, 27-45. doi:10.1177/1073191105283504

Baumeister, R. F., Bratslavsky, E., Muraven, M., \& Tice, D. M. (1998). Ego depletion: Is the active self a limited resource? Journal of Personality and Social Psychology, 74, 1252-1265. doi:10.1037/0022-3514.74 .5 .1252
Beckers, D. G. J., van der Linden, D., Smulders, P. G. W., Kompier, M. A. J., Taris, T. W., \& Geurts, S. A. E. (2008). Voluntary or involuntary? Control over overtime and rewards for overtime in relation to fatigue and work satisfaction. Work \& Stress, 22, 33-50. doi:10.1080/ 02678370801984927

Bishop, S. R., Lau, M., Shapiro, S., Carlson, L., Anderson, N. D., Carmody, J., . . Devins, G. (2004). Mindfulness: A proposed operational definition. Clinical Psychology: Science and Practice, 11, 230-241. doi:10.1093/clipsy.bph077

Bliese, P. D. (2006). Multilevel modeling in R (2.2): A brief introduction to $R$, the multilevel package and the nlme package. Washington, DC: Walter Reed Army Institute of Research.

Bliese, P. D., \& Jex, S. M. (2002). Incorporating a multilevel perspective into occupational stress research: Theoretical, methodological, and practical implications. Journal of Occupational Health Psychology, 7, 265276. doi:10.1037/1076-8998.7.3.265

Bliese, P. D., \& Ployhart, R. E. (2002). Growth modeling using random coefficient models: Model building, testing, and illustrations. Organizational Research Methods, 5, 362-387. doi:10.1177/109442802237116

Bohlmeijer, E., Prenger, R., Taal, E., \& Cuijpers, P. (2010). The effects of mindfulness-based stress reduction therapy on mental health of adults with a chronic disease: A meta-analysis. Journal of Psychosomatic Research, 68, 539-544. doi:10.1016/j.jpsychores.2009.10.005

Bono, J. E., Foldes, H. J., Vinson, G., \& Muros, J. P. (2007). Workplace emotions: The role of supervision and leadership. Journal of Applied Psychology, 92, 1357-1367. doi:10.1037/0021-9010.92.5.1357

Bono, J. E., \& Judge, T. (2003). Self-concordance at work: Towards understanding motivational effects of transformational leaders. Academy of Management Journal, 46, 554-571. doi:10.2307/30040649

Borders, A., Earleywine, M., \& Jajodia, A. (2010). Could mindfulness decrease anger, hostility, and aggression by decreasing rumination? Aggressive Behavior, 36, 28-44. doi:10.1002/ab.20327

Bowlin, S. L., \& Baer, R. A. (2012). Relationships between mindfulness, self-control, and psychological functioning. Personality and Individual Differences, 52, 411-415. doi:10.1016/j.paid.2011.10.050

Brotheridge, C. M., \& Lee, R. T. (2002). Testing a conservation of resources model of the dynamics of emotional labor. Journal of Occupational Health Psychology, 7, 57-67. doi:10.1037/1076-8998.7.1.57

Brown, K. W., Kasser, T., Ryan, R. M., Linley, A., \& Orzech, K. (2009). When what one has is enough: Mindfulness, financial desire discrepancy, and subjective well-being. Journal of Research in Personality, 43, 727-736. doi:10.1016/j.jrp.2009.07.002

Brown, K. W., \& Ryan, R. M. (2003). The benefits of being present: Mindfulness and its role in psychological well-being. Journal of Personality and Social Psychology, 84, 822-848. doi:10.1037/0022-3514 .84 .4 .822

Brown, K. W., \& Ryan, R. M. (2004). Perils and promise in defining and measuring mindfulness: Observations from experience. Clinical Psychology: Science and Practice, 11, 242-248. doi:10.1093/clipsy.bph078

Brown, K. W., Ryan, R. M., \& Creswell, J. D. (2007). Mindfulness: Theoretical foundations and evidence for its salutary effects. Psychological Inquiry, 18, 211-237. doi:10.1080/10478400701598298

Brown, K. W., Ryan, R. M., Loverich, T. M., Biegel, G. M., \& West, A. M. (2011). Out of the armchair and into the streets: Measuring mindfulness advances knowledge and improves interventions: Reply to Grossman (2011). Psychological Assessment, 23, 1041-1046. doi:10.1037/ a0025781

Brown, K. W., West, A. M., Loverich, T. M., \& Biegel, G. M. (2011). Assessing adolescent mindfulness: Validation of an Adapted Mindful Attention Awareness Scale in adolescent normative and psychiatric populations. Psychological Assessment, 23, 1023-1033. doi:10.1037/ a0021338

Büssing, A., \& Perrar, K. M. (1992). Die Messung von Burnout: Untersuchung einer deutschen Fassung des Maslach Burnout Inventory 
(MBI-D) [Measuring burnout: An investigation of a German version of the Maslach Burnout Inventory (MBI-D)]. Diagnostica, 38, 328-353.

Chambers, R., Gullone, E., \& Allen, N. B. (2009). Mindful emotion regulation: An integrative review. Clinical Psychology Review, 29, 560572. doi:10.1016/j.cpr.2009.06.005

Chiesa, A., Calati, R., \& Serretti, A. (2011). Does mindfulness training improve cognitive abilities? A systematic review of neuropsychological findings. Clinical Psychology Review, 31, 449-464. doi:10.1016/j.cpr .2010 .11 .003

Chiesa, A., \& Serretti, A. (2009). Mindfulness-based stress reduction for stress management in healthy people: A review and meta-analysis. The Journal of Alternative and Complementary Medicine, 15, 593-600. doi:10.1089/acm.2008.0495

Coffey, K. A., \& Hartman, M. (2008). Mechanisms of action in the inverse relationship between mindfulness and psychological distress. Complementary Health Practice Review, 13, 79-91. doi:10.1177/ 1533210108316307

Cohen-Katz, J., Wiley, S. D., Capuano, T., Baker, M. A., \& Shapiro, S. (2005). The effects of mindfulness-based stress reduction on nurse stress and burnout, Part II: A quantitative and qualitative study. Holistic Nursing Practice, 19, 26-35.

Collard, P., Avny, N., \& Boniwell, I. (2008). Teaching mindfulness based cognitive therapy (MBCT) to students: The effects of MBCT on the levels of mindfulness and subjective well-being. Counselling Psychology Quarterly, 21, 323-336. doi:10.1080/09515070802602112

Côté, S. (2005). A social interaction model of the effects of emotion regulation on work strain. The Academy of Management Review, 30, 509-530. doi:10.5465/AMR.2005.17293692

Côté, S., \& Morgan, L. M. (2002). A longitudinal analysis of the association between emotion regulation, job satisfaction, and intentions to quit. Journal of Organizational Behavior, 23, 947-962. doi:10.1002/job.174

Cropanzano, R., Rupp, D. E., \& Byrne, Z. S. (2003). The relationship of emotional exhaustion to work attitudes, job performance, and organizational citizenship behaviors. Journal of Applied Psychology, 88, 160169. doi:10.1037/0021-9010.88.1.160

Dane, E. (2011). Paying attention to mindfulness and its effects on task performance in the workplace. Journal of Management, 37, 997-1018. doi: $10.1177 / 0149206310367948$

Davidson, R. J. (2010). Empirical explorations of mindfulness: Conceptual and methodological conundrums. Emotion, 10, 8-11. doi:10.1037/ a0018480

Deci, E. L., \& Ryan, R. M. (1985). Intrinsic motivation and selfdetermination in human behavior. New York, NY: Plenum Press.

Diefendorff, J. M., Richard, E. M., \& Yang, J. X. (2008). Linking emotion regulation strategies to affective events and negative emotions at work. Journal of Vocational Behavior, 73, 498-508. doi:10.1016/j.jvb.2008 .09 .006

Enders, C. K., \& Tofighi, D. (2007). Centering predictor variables in cross-sectional multilevel models: A new look at an old issue. Psychological Methods, 12, 121-138. doi:10.1037/1082-989X.12.2.121

Erisman, S. M., \& Roemer, L. (2010). A preliminary investigation of the effects of experimentally induced mindfulness on emotional responding to film clips. Emotion, 10, 72-82. doi:10.1037/a0017162

Feldman, G., Hayes, A., Kumar, S., Greeson, J., \& Laurenceau, J.-P. (2007). Mindfulness and emotion regulation: The development and initial validation of the Cognitive and Affective Mindfulness ScaleRevised (CAMS-R). Journal of Psychopathology and Behavioral Assessment, 29, 177-190. doi:10.1007/s10862-006-9035-8

Fetterman, A. K., Robinson, M. D., Ode, S., \& Gordon, K. H. (2010). Neuroticism as a risk factor for behavioral dysregulation: A mindfulness-mediation perspective. Journal of Social and Clinical Psychology, 29, 301-321. doi:10.1521/jscp.2010.29.3.301

Finkel, S. E. (1995). Causal analysis with panel data. Thousand Oaks, CA: Sage.
Fredrickson, B. L., Cohn, M. A., Coffey, K. A., Pek, J., \& Finkel, S. M. (2008). Open hearts build lives: Positive emotions, induced through loving-kindness meditation, build consequential personal resources. Journal of Personality and Social Psychology, 95, 1045-1062. doi: $10.1037 / \mathrm{a} 0013262$

Galantino, M. L., Baime, M., Maguire, M., Szapary, P. O., \& Farrar, J. T. (2005). Association of psychological and physiological measures of stress in health-care professionals during an 8-week mindfulness meditation program: Mindfulness in practice. Stress and Health, 21, 255-261. doi:10.1002/smi.1062

George, J. M., \& Jones, G. R. (1996). The experience of work and turnover intentions: Interactive effects of value attainment, job satisfaction, and positive mood. Journal of Applied Psychology, 81, 318-325. doi: 10.1037/0021-9010.81.3.318

Glomb, T. M., Duffy, M. K., Bono, J. E., \& Yang, T. (2011). Mindfulness at work. In J. Martocchio, H. Liao, \& A. Joshi (Eds.), Research in personnel and human resource management (pp. 115-157). doi: 10.1108/S0742-7301(2011)0000030005

Grandey, A. A. (2000). Emotional regulation in the workplace: A new way to conceptualize emotional labor. Journal of Occupational Health Psychology, 5, 95-110. doi:10.1037/1076-8998.5.1.95

Grandey, A. A. (2003). When "the show must go on": Surface acting and deep acting as determinants of emotional exhaustion and peer-rated service delivery. Academy of Management Journal, 46, 86-96. doi: $10.2307 / 30040678$

Grandey, A. A., \& Diamond, J. A. (2010). Interactions with the public: Bridging job design and emotional labor perspectives. Journal of Organizational Behavior, 31, 338-350. doi:10.1002/job.637

Grandey, A. A., Dickter, D. N., \& Sin, H. (2004). The customer is not always right: Customer aggression and emotion regulation of service employees. Journal of Organizational Behavior, 25, 397-418. doi: $10.1002 /$ job. 252

Grandey, A. A., Tam, A. P., \& Brauburger, A. L. (2002). Affective states and traits in the workplace: Diary and survey data from young workers. Motivation and Emotion, 26, 31-55. doi:10.1023/A:1015142124306

Gross, J. J. (1998a). Antecedent- and response-focused emotion regulation: Divergent consequences for experience, expression, and physiology. Journal of Personality and Social Psychology, 74, 224-237. doi: 10.1037/0022-3514.74.1.224

Gross, J. J. (1998b). The emerging field of emotion regulation: An integrative review. Review of General Psychology, 2, 271-299. doi:10.1037/ 1089-2680.2.3.271

Grossman, P., Niemann, L., Schmidt, S., \& Walach, H. (2004) Mindfulness-based stress reduction and health benefits: A meta-analysis Journal of Psychosomatic Research, 57, 35-43. doi:10.1016/S0022 3999(03)00573-7

Halbesleben, J. R. B., \& Bowler, W. M. (2007). Emotional exhaustion and job performance: The mediating role of motivation. Journal of Applied Psychology, 92, 93-106. doi:10.1037/0021-9010.92.1.93

Hariri, A. R., Bookheimer, S. Y., \& Mazziotta, J. C. (2000). Modulating emotional responses: Effects of a neocortical network on the limbic system. NeuroReport, 11, 43-48. doi:10.1097/00001756-20000117000009

Harrison, D. A., Newman, D. A., \& Roth, P. L. (2006). How important are job attitudes? Meta-analytic comparisons of integrative behavioral outcomes and time sequences. Academy of Management Journal, 49, 305325. doi:10.5465/AMJ.2006.20786077

Hayes, A. M., \& Feldman, G. (2004). Clarifying the construct of mindfulness in the context of emotion regulation and the process of change in therapy. Clinical Psychology: Science and Practice, 11, 255-262. doi: 10.1093/clipsy.bph080

Heppner, W. L., Kernis, M. H., Lakey, C. E., Campbell, W. K., Goldman, B. M., Davis, P. J., \& Cascio, E. V. (2008). Mindfulness as a means of 
reducing aggressive behavior: Dispositional and situational evidence. Aggressive Behavior, 34, 486-496. doi:10.1002/ab.20258

Hochschild, A. R. (1983). The managed heart. Berkeley, CA: University of California Press.

Holman, D., Martínez-Iñigo, D., \& Totterdell, P. (2008). Emotional labour and employee well-being: An integrative review. In N. M. Ashkanasy \& C. L. Cooper (Eds.), Research companion to emotion in organizations (pp. 301-315). Northampton, MA: Edward Elgar.

Hox, J. (2002). Multilevel analysis: Techniques and applications. Mahwah, NJ: Erlbaum.

Hülsheger, U. R., Lang, J. W. B., \& Maier, G. W. (2010). Emotional labor, strain, and performance: Testing reciprocal relationships in a longitudinal panel study. Journal of Occupational Health Psychology, 15, 505521. doi:10.1037/a0021003

Hülsheger, U. R., \& Schewe, A. F. (2011). On the costs and benefits of emotional labor: A meta-analysis spanning three decades of research. Journal of Occupational Health Psychology, 16, 361-389. doi:10.1037/ a0022876

Irving, J. A., Dobkin, P. L., \& Park, J. (2009). Cultivating mindfulness in health care professionals: A review of empirical studies of mindfulnessbased stress reduction (MBSR). Complementary Therapies in Clinical Practice, 15, 61-66. doi:10.1016/j.ctcp.2009.01.002

Jain, S., Shapiro, S. L., Swanick, S., Roesch, S. C., Mills, P. J., Bell, I., \& Schwartz, G. E. R. (2007). A randomized controlled trial of mindfulness meditation versus relaxation training: Effects on distress, positive states of mind, rumination, and distraction. Annals of Behavioral Medicine, 33, 11-21. doi:10.1207/s15324796abm3301_2

Judge, T. A., Bono, J. E., Erez, A., \& Locke, E. A. (2005). Core selfevaluations and job and life satisfaction: The role of self-concordance and goal attainment. Journal of Applied Psychology, 90, 257-268. doi:10.1037/0021-9010.90.2.257

Judge, T. A., Locke, E. A., Durham, C. C., \& Kluger, A. N. (1998). Dispositional effects on job and life satisfaction: The role of core evaluations. Journal of Applied Psychology, 83, 17-34. doi:10.1037/ 0021-9010.83.1.17

Judge, T. A., Woolf, E. F., \& Hurst, C. (2009). Is emotional labor more difficult for some than for others? A multilevel, experience-sampling study. Personnel Psychology, 62, 57-88. doi:10.1111/j.1744-6570.2008 .01129.x

Kabat-Zinn, J. (1982). An outpatient program in behavioral medicine for chronic pain patients based on the practice of mindfulness meditation: Theoretical considerations and preliminary results. General Hospital Psychiatry, 4, 33-47. doi:10.1016/0163-8343(82)90026-3

Kiken, L. G., \& Shook, N. J. (2012). Mindfulness and emotional distress: The role of negatively biased cognition. Personality and Individual Differences, 52, 329-333. doi:10.1016/j.paid.2011.10.031

Krasner, M. S., Epstein, R. M., Beckman, H., Suchman, A. L., Chapman, B., Mooney, C. J., \& Quill, T. E. (2009). Association of an educational program in mindful communication with burnout, empathy, and attitudes among primary care physicians. JAMA: Journal of the American Medical Association, 302, 1284-1293. doi:10.1001/jama.2009.1384

Kristeller, J. L., \& Rikhye, K. (2008). Meditative traditions and contemporary psychology. In K. R. Rao, A. C. Paranjpe, \& A. K. Dalal (Eds.), Handbook of Indian psychology (pp. 506-538). doi:10.1017/ UPO9788175968448.028

Kuan, T. (2008). Mindfulness in early Buddhism: New approaches through psychology and textual analysis of Pali, Chinese, and Sanskrit sources. New York, NY: Routledge.

Lau, M. A., Bishop, S. R., Zindel, S., Buis, T., Anderson, N. D., Carlson, L., . . Devins, G. (2006). The Toronto Mindfulness Scale: Development and validation. Journal of Clinical Psychology, 62, 1445-1467. doi:10 $.1002 /$ jclp. 20326

Lazarus, R. S., \& Folkman, S. (1984). Stress, appraisal, and coping. New York, NY: Springer.
Lee, R. T., \& Brotheridge, C. M. (2011). Words from the heart speak to the heart: A study of deep acting, faking, and hiding among child care workers. Career Development International, 16, 401-420. doi:10.1108/ 13620431111158805

Leidner, R. (1999). Emotional labor in service work. The ANNALS of the American Academy of Political and Social Science, 561, 81-95. doi: 10.1177/0002716299561001006

Marcks, B. A., \& Woods, D. W. (2005). A comparison of thought suppression to an acceptance-based technique in the management of personal intrusive thought: A controlled evaluation. Behaviour Research and Therapy, 43, 433-445. doi:10.1016/j.brat.2004.03.005

Martínez-Iñigo, D., Totterdell, P., Alcover, C., \& Holman, D. (2007). Emotional labour and emotional exhaustion: Interpersonal and intrapersonal mechanisms. Work \& Stress, 21, 30-47. doi:10.1080/ 02678370701234274

Maslach, C., \& Jackson, S. E. (1981). The measurement of experienced burnout. Journal of Organizational Behavior, 2, 99-113. doi:10.1002/ job.4030020205

Maslach, C., \& Jackson, S. E. (1984). The Maslach Burnout Inventory. Palo Alto, CA: Consulting Psychologists Press.

Maslach, C., Schaufeli, W. B., \& Leiter, M. P. (2001). Job burnout. Annual Review of Psychology, 52, 397-422. doi:10.1146/annurev.psych.52.1 .397

Muthén, L. K., \& Muthén, B. O. (2007). Mplus user's guide (5th ed.). Los Angeles, CA: Muthén \& Muthén.

Niemiec, C. P., Brown, K. W., Kashdan, T. B., Cozzolino, P. J., Breen, W. E., \& Levesque-Bristol, C. (2010). Being present in the face of existential threat: The role of trait mindfulness in reducing defensive responses to mortality salience. Journal of Personality and Social Psychology, 99, 344-365. doi:10.1037/a0019388

Örtqvist, D., \& Wincent, J. (2010). Role stress, exhaustion, and satisfaction: A cross-lagged structural equation modeling approach supporting Hobfoll's loss spirals. Journal of Applied Social Psychology, 40, 13571384. doi:10.1111/j.1559-1816.2010.00621.x

Preacher, K. J., Zhang, Z., \& Zyphur, M. J. (2011). Alternative methods for assessing mediation in multilevel data: The advantage of multileve SEM. Structural Equation Modeling, 18, 161-182. doi:10.1080/ 10705511.2011.557329

Preacher, K. J., Zyphur, M. J., \& Zhang, Z. (2010). A general multilevel SEM framework for assessing multilevel mediation. Psychological Methods, 15, 209-233. doi:10.1037/a0020141

Querstret, D., \& Cropley, M. (2012). Exploring the relationship between work-related rumination, sleep quality, and work-related fatigue. Journal of Occupational Health Psychology, 17, 341-353. doi:10.1037/ a0028552

Rafaeli, A., \& Sutton, R. I. (1987). Expression of emotion as part of the work role. The Academy of Management Review, 12, 23-37. doi: 10.5465/AMR.1987.4306444

Richardson, K. M., \& Rothstein, H. R. (2008). Effects of occupational stress management intervention programs: A meta-analysis. Journal of Occupational Health Psychology, 13, 69-93. doi:10.1037/1076-8998.13 .1 .69

Robins, C. J., Keng, S.-L., Ekblad, A. G., \& Brantley, J. G. (2012). Effects of mindfulness-based stress reduction on emotional experience and expression: A randomized controlled trial. Journal of Clinical Psychology, 68, 117-131. doi:10.1002/jclp.20857

Roemer, L., \& Orsillo, S. M. (2003). Mindfulness: A promising intervention strategy in need for further study. Clinical Psychology: Science and Practice, 10, 172-178. doi:10.1093/clipsy.bpg020

Ryan, R. M., \& Deci, E. L. (2008). From ego depletion to vitality: Theory and findings concerning the facilitation of energy available to the self Social and Personality Psychology Compass, 2, 702-717. doi:10.1111/ j.1751-9004.2008.00098.x 
Sanharakshita. (2004). Living with kindness: The Buddha's teaching on metta. Birmingham, England: Windhorse.

Sedlmeier, P., Eberth, J., Schwarz, M., Zimmermann, D., Haarig, F., Jaeger, S., \& Kunze, S. (2012). The psychological effects of meditation: A meta-analysis. Psychological Bulletin, 138, 1139-1171. doi:10.1037/ a0028168

Segal, Z., Williams, M. R., \& Teasdale, J. (2002). Mindfulness-based cognitive therapy for depression: A new approach to preventing relapse. New York, NY: Guilford Press.

Shapiro, S. L., \& Carlson, L. E. (2009). The art and science of mindfulness: Integrating mindfulness into psychology and the helping professions. doi:10.1037/11885-000

Shapiro, S. L., Carlson, L. E., Astin, J. A., \& Freedman, B. (2006). Mechanisms of mindfulness. Journal of Clinical Psychology, 62, 373386. doi: $10.1002 /$ jclp. 20237

Siegel, R. D. (2010). The mindful solution: Everyday practices for everyday problems. New York, NY: Guilford Press.

Teuchmann, K., Totterdell, P., \& Parker, S. K. (1999). Rushed, unhappy, and drained: An experience sampling study of relations between time pressure, perceived control, mood, and emotional exhaustion in a group of accountants. Journal of Occupational Health Psychology, 4, 37-54. doi:10.1037/1076-8998.4.1.37

Totterdell, P., \& Holman, D. (2003). Emotion regulation in customer service roles: Testing a model of emotional labor. Journal of Occupational Health Psychology, 8, 55-73. doi:10.1037/1076-8998.8.1.55

Walach, H., Buchheld, N., Buttenmüller, V., Kleinknecht, N., \& Schmidt, S. (2006). Measuring mindfulness: The Freiburg Mindfulness Inventory (FMI). Personality and Individual Differences, 40, 1543-1555. doi: 10.1016/j.paid.2005.11.025

Weinstein, N., Brown, K. W., \& Ryan, R. M. (2009). A multi-method examination of the effects of mindfulness on stress attribution, coping, and emotional well-being. Journal of Research in Personality, 43, 374385. doi:10.1016/j.jrp.2008.12.008
Weiss, H. M. (2002). Deconstructing job satisfaction: Separating evaluations, beliefs and affective experiences. Human Resource Management Review, 12, 173-194. doi:10.1016/S1053-4822(02)00045-1

Weiss, H. M., \& Cropanzano, R. (1996). Affective events theory: A theoretical discussion of the structure, causes and consequences of affective experiences at work. In B. M. Staw \& L. L. Cummings (Eds.), Research in organizational behavior: An annual series of analytical essays and critical reviews (Vol. 18, pp. 1-74). London, England: JAI Press.

Williams, L. J., \& Podsakoff, P. M. (1989). Longitudinal field methods for studying reciprocal relationships in organizational behavior research: Toward improved causal analysis. In B. M. Staw \& L. L. Cummings (Eds.), Research in organizational behavior (Vol. 11, pp. 247-292). London, England: JAI Press.

Williams, M., Teasdale, J., Segal, Z., \& Kabat-Zinn, J. (2007). The mindful way through depression: Freeing yourself from chronic unhappiness. New York, NY: Guilford Press.

Wolever, R. Q., Bobinet, K. J., McCabe, K., Mackenzie, E. R., Fekete, E., Kusnick, C. A., \& Baime, M. (2012). Effective and viable mind-body stress reduction in the workplace: A randomized controlled trial. Journal of Occupational Health Psychology, 17, 246-258. doi:10.1037/ a0027278

Ybema, J. F., Smulders, P. G. W., \& Bongers, P. M. (2010). Antecedents and consequences of employee absenteeism: A longitudinal perspective on the role of job satisfaction and burnout. European Journal of Work and Organizational Psychology, 19, 102-124. doi:10.1080/ 13594320902793691

Received June 7, 2011

Revision received October 12, 2012 Accepted November 21, 2012

\section{E-Mail Notification of Your Latest Issue Online!}

Would you like to know when the next issue of your favorite APA journal will be available online? This service is now available to you. Sign up at http://notify.apa.org/ and you will be notified by e-mail when issues of interest to you become available! 